Navy Personnel Research and Development Center

San Diego, California 92152-7250 TR-96-2 October 1995

\title{
Evaluation of a Celestial Navigation Refresher Course Delivered by Videoteletraining
}

C. Douglas Wetzel
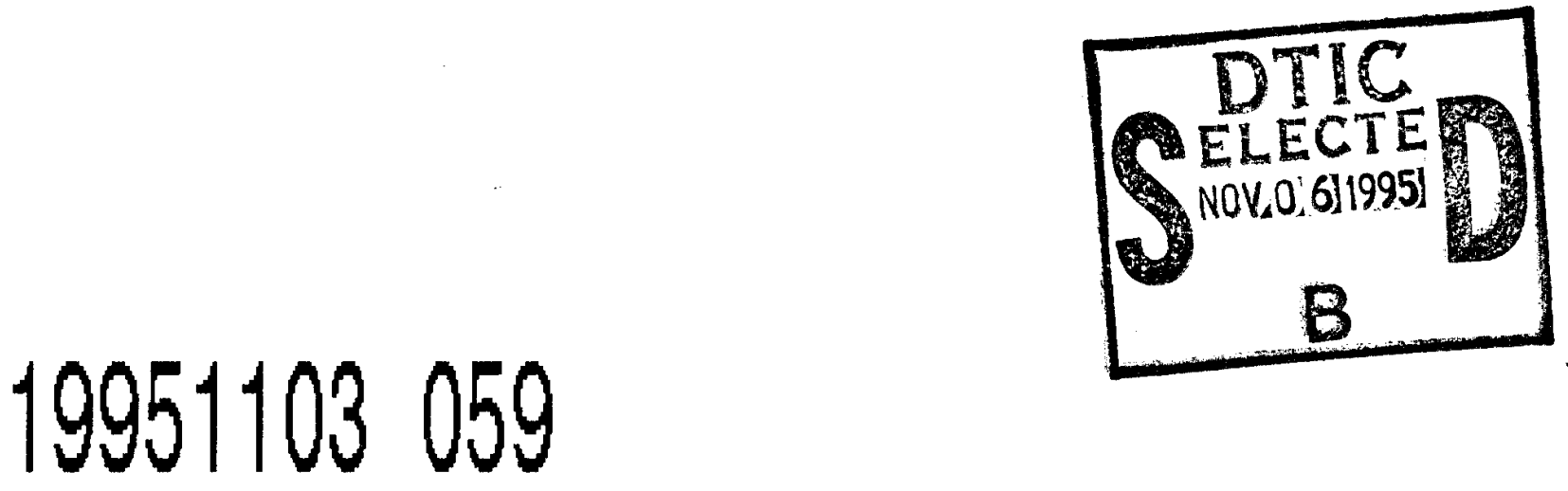

DTTC QU ALUTY INBPECTED I 


\title{
Evaluation of a Celestial Navigation Refresher Course Delivered by Videoteletraining
}

C. Douglas Wetzel

Reviewed by

Orvin A. Larson

Approved by

J. C. McLachlan

\author{
Released by \\ P. M. Spishock \\ Captain, U.S. Navy \\ Commanding Officer \\ and \\ Murray Rowe \\ Technical Director
}

Approved for public release;

distribution is unlimited.

Navy Personnel Research and Development Center

San Diego, California 92152-7250 


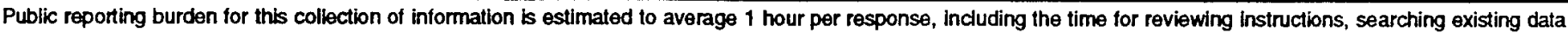

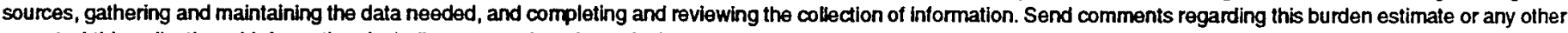

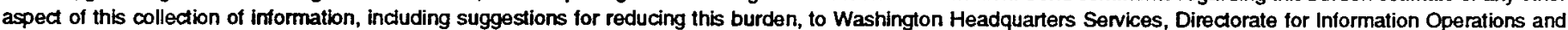

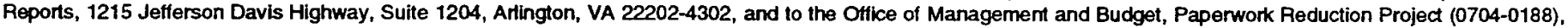
Washington, DC 20503.

\begin{tabular}{l|l} 
1. AGENCY USE ONLY (Leave blank) & $\begin{array}{r}\text { 2. REPORT DATE } \\
\text { October } 1995\end{array}$ \\
\hline
\end{tabular}

4. TITLE AND SUBTITLE

Evaluation of a Celestial Navigation Refresher Course Delivered by Videoteletraining

6. AUTHOR(S)

C. Douglas Wetzel

7. PERFORMING ORGANIZATION NAME(S) AND ADDRESS(ES)

Navy Personnel Research and Development Center

53335 Ryan Road

San Diego, CA $92152-7250$

9. SPONSORING/MONITORING AGENCY NAME(S) AND ADDRESS(ES)

Chief of Naval Personnel (PERS-00H)

Navy Annex

Washington, DC 20370-0000

3. REPORT TYPE AND DATE COVERED Interim

5. FUNDING NUMBERS

Program Element: 0603707N

Work Unit: 01772.ET112

11. SUPPLEMENTARY NOTES

Functional Area: Training Research

Product Line: Schoolhouse Training

Effort: Distributed Training Technology

12a. DISTRIBUTION/AVAILABILITY STATEMENT

Approved for public release; distribution is unlimited.

12b. DISTRIBUTION CODE

A

13. ABSTRACT (Maximum 200 words)

The use of videoteletraining (VTT) to deliver a Celestial Navigation course was evaluated. Three treatment groups were compared with a total of 279 students: (1) traditional classrooms; (2) VTT local classrooms with an instructor and students, and (3) VTT remote classrooms where students were connected to the local classroom by a two-way audio and video VTT system. Student performance on homework during the week was similar among groups, VTT remote students were slightly lower than local students on a final examination, but similar numbers of students passed the course. An interaction tally of instructor and student questions showed slightly fewer interactions per hour for VTT remote sites than for the local site where there were more students. However, there was no disadvantage for VTT remote students when examined on a per student per hour basis. Responses on a student questionnaire were generally positive and remote site students responded only slightly less favorably than local site students. Remote students were more favorable toward the use of a picture-in-picture display showing both an instructor and visuals during lengthy periods when the instructor would normally have been off screen. The evaluation showed that delivery of the course by videoteletraining has been successful and can be expanded to other sites in order to reduce travel costs.

14. SUBJECT TERMS

Military training, distance education, videoteletraining, interactive television, instructional television, picture-in-picture (PIP) display

15. NUMBER OF PAGES 77

16. PRICE CODE

20. LIMITATION OF ABSTRACT

17. SECURITY CLASSIFICATION OF REPORT UNCLASSIFIED
19. SECURITY CLASSIFICATION OF ABSTRACT UNCLASSIFIED
UNLIMITED 


\section{Foreword}

This report describes research conducted as part of the Navy Personnel Research and Development Center's Distributed Training Technology (DTT) project. The DTT project is part of our Classroom and Afloat Training research program and falls under the Education and Training project (L1772) of the Navy's Manpower, Personnel, and Training Advanced Development Program Element $(0603707 \mathrm{~N})$. The work was performed under the sponsorship of the Bureau of Naval Personnel. The research is evaluating technologies, training strategies, procedures, and management methods to extend videoteletraining (VTT) beyond traditional, lecture-based courses.

The research investigated the feasibility of using videoteletraining to deliver a Celestial Navigation course. The findings have direct implications for the design of future distance education systems in the Navy and elsewhere.

The recommendations in this report are intended for use by the Chief of Naval Education and Training and Bureau of Naval Personnel in developing policy for the application of VTT in the Navy.

P. M. SPISHOCK

Captain, U.S. Navy Commanding Officer
MURRAY W. ROWE

Technical Director

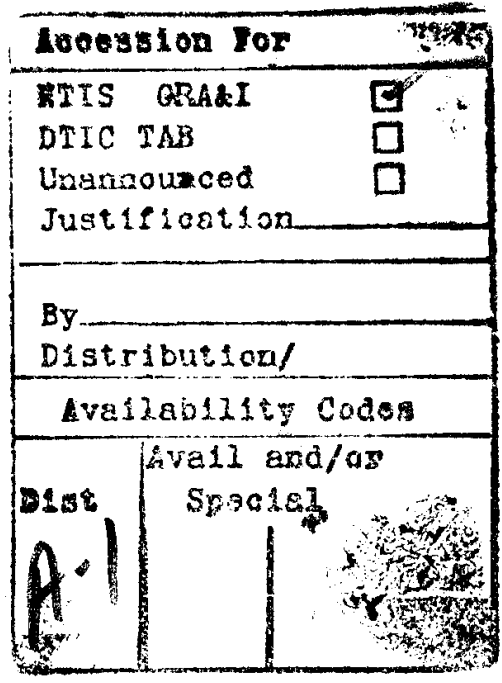




\section{Summary}

\section{Problem and Background}

Many Navy personnel requiring training are geographically separated from training resources. Videoteletraining (VTT) enables an instructor to teach multiple classes at different geographic locations. VTT has been shown to be an efficient and cost beneficial way to deliver training, and is now in operational use by the Chief of Naval Education and Training (CNET) within the CNET Electronic Schoolhouse Network (CESN). VTT has been used to deliver lecture-based instruction and the cost benefits of VTT could be extended if other types of course content could be delivered, such as courses with student laboratories. A Celestial Navigation course presented challenges for conversion to the VTT format because it contained several aspects that departed from those found in the typical lecture-based course. The course uses various visuals with detailed print from nautical tables and contains hands-on laboratories involving difficult computations and plotting. Concern also exists for assisting remote site students in resolving problems with computations.

\section{Objective}

The objective of this research was to evaluate the feasibility of delivering a Celestial Navigation refresher course by video teletraining (VTT) in terms of the effects of VTT on student performance, student attitudes toward the training, and instructor-student interaction.

\section{Approach}

Three treatment groups were compared: (1) traditional classrooms; (2) VTT local classrooms with an instructor and students, and (3) VTT remote classrooms where students were connected to the local classroom by a two-way audio and video VTT system. A total of 279 students were in regular offerings of nine VTT classes (135 local and 66 remote students) and five traditional classes (78 students). The treatment groups were compared in terms of student academic performance, student questionnaire responses, and an observer tally of instructor-student interaction.

\section{Results and Conclusions}

Student academic performance was generally at a high level over three measures of performance. There were no significant differences between the treatment groups on homework during the week. There was a small but statistically significant decrement in final examination scores for remote students, but there was no significant difference between groups in the percentage of students passing the course. Statistically controlling final examination scores for inequities in student characteristics due to different enrollment patterns at the sites showed an adjusted mean difference of about $4 \%$ between local and remote sites when officer-enlisted and military seniority status were controlled.

Student responses on questionnaire rating items were higher for VTT local and traditional students than for VTT remote students. However, the magnitude of differences between groups was generally small. Ratings for all groups were generally high and in a positive direction, and the observed pattern was typical of that found in previous VTT research. The differences between groups were negligible for topics concerned with class participation, hearing and seeing the 
instruction, and instructor presentations. Remote students gave slightly lower ratings than local students on topics related to getting assistance or attention, but did not rate the difficulty or pace of the course significantly different. Remote students were more likely to agree that they had less access to and interaction with the instructor, and to identify other students as a source of assistance outside of class. However, remote students were equally willing to take another VTT course and their preferences for a method of instruction for this course were not less favorable than local students. Remote students also strongly preferred a Picture-in-Picture (PIP) display that showed both the instructor and visuals during periods when the instructor normally would have been offscreen. Facilities related questions indicated that table space for publications and plotting was more confined at some sites.

An observer's tally of interactions during lectures indicated that there were adequate levels of remote site student participation and instructor interaction with remote students. Interactions were most commonly initiated by instructors with a mix of questions that were left open to any site, directed at a site, or directed at individual students identified from a roster. This mixture allowed the instructor to assess computational knowledge in students likely to respond when they knew an answer, as well as those individuals that were less likely to participate. There tended to be fewer interactions per hour associated with remote sites because there were fewer students than at the local site. However, remote students were not disadvantaged when these interactions were expressed in terms relative to the number of students (per student per hour). In these terms, remote site students received a higher rate of instructor questions associated with their site than did local students. After the first day of class, student initiated questions increased, unanswered instructor questions decreased, and instructor reminders for local site students to use their microphones declined.

The Celestial Navigation refresher course was successfully adapted for delivery by videoteletraining. The course has been regularly offered to remote VTT sites without problem and is accepted by students and instructors. The initial concerns with the feasibility of delivering the course were overcome as a result of several course conversion techniques and the efforts of the instructors to monitor remote site students. The adaptation of this course and its small print visuals, strip forms, and test scoring techniques provide an illustrative example of a VTT conversion methodology applicable to other courses.

\section{Recommendations}

The following recommendations are for the Chief of Naval Education and Training and the CNET Electronic Schoolhouse Network.

1. Delivery of the Celestial Navigation refresher course by videoteletraining has been successful and the use of this method should be expanded to other sites as appropriate to satisfy demand for the course.

2. VTT courses with atypical requirements such as student laboratories should be given special attention to maintain a high quality VTT version of the course. Such attention includes monitoring remote site student comprehension, conveying VTT lessons learned as remote site facilitators and instructors rotate in their assignments, and providing sufficient space for the additional instructional materials found in this and other future laboratory courses. 


\section{Contents}

Introduction

Problem

Objective

Background

Method

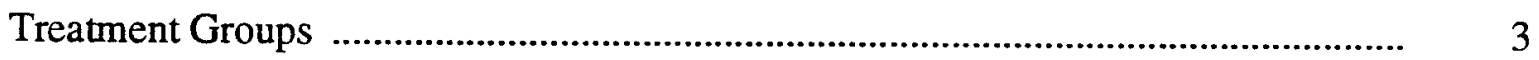

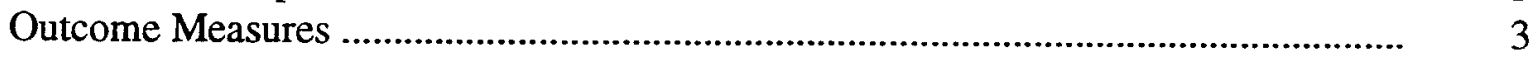

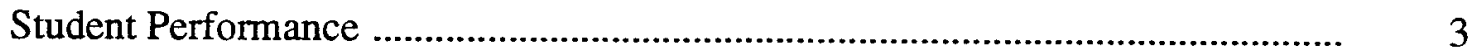

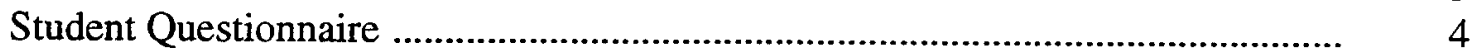

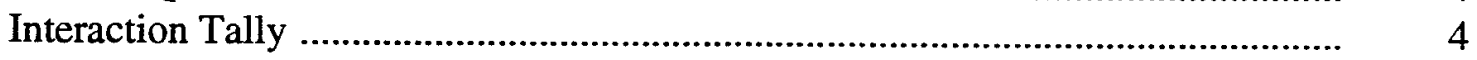

Subjects and Classes Observed ........................................................................ 5

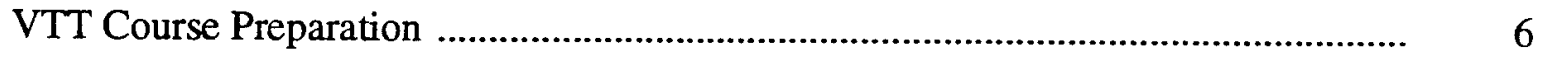

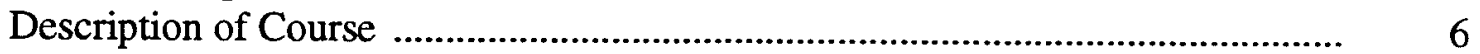

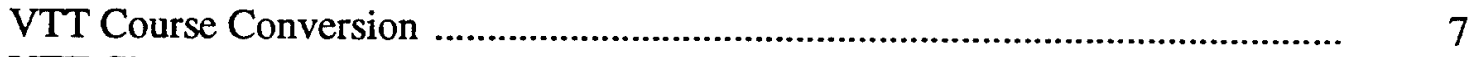

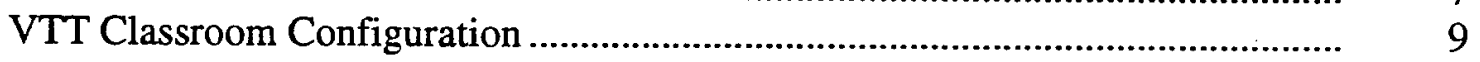

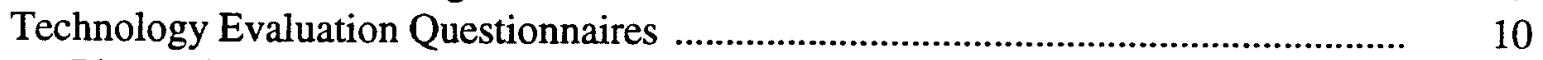

Picture-in-Picture Evaluation ................................................................... 10

Electronic Presentation Program Evaluation .................................................. 12

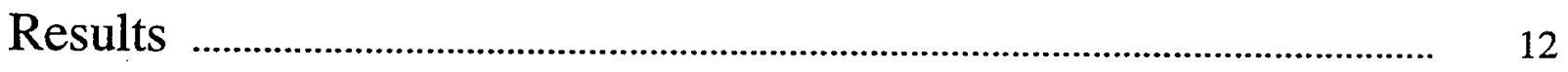

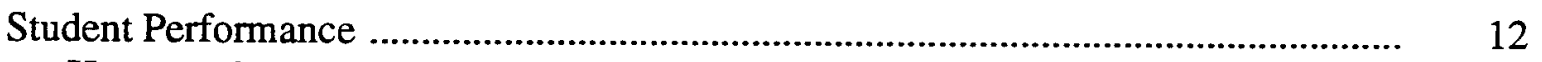

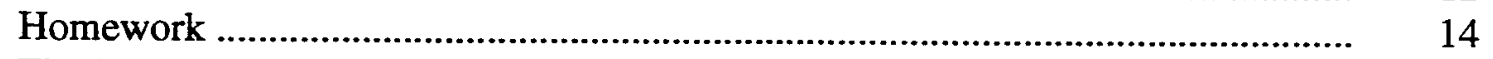

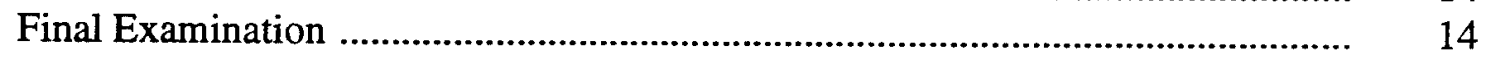

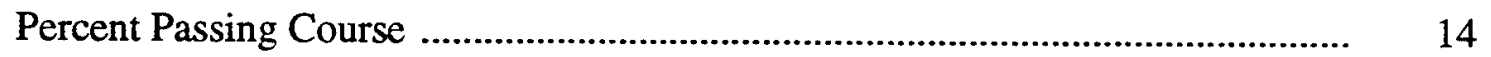

Discussion of Performance .......................................................................... 15

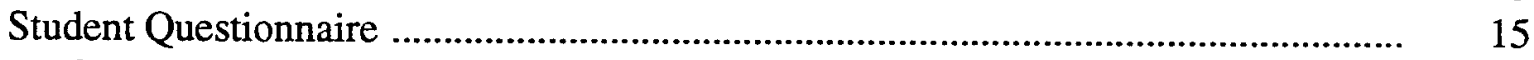

Student Prior Experience and Background ....................................................... 15

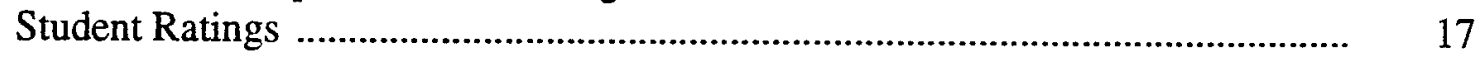

Multiple Choice Items ............................................................................... 24

Open-Ended Questions ................................................................................. 27

Summary of Related Questionnaire Topics ..................................................... 28

Instructor-Student Interaction and Class Participation .......................................... 29

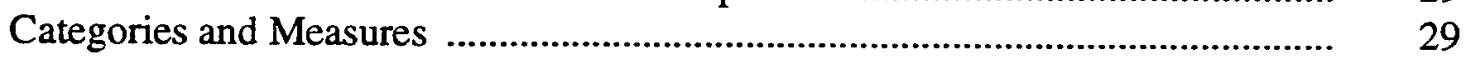

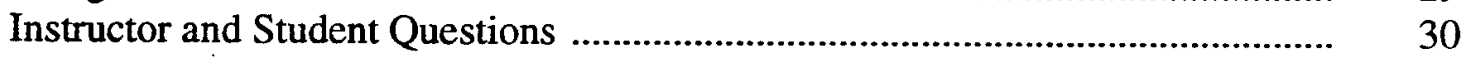

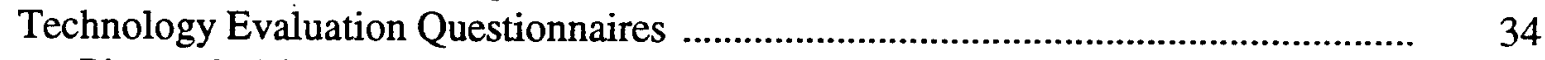

Picture-in-Picture Evaluation ................................................................... 34

Electronic Presentation Program Evaluation ................................................ 37 
Discussion

Student Performance

Student Attitudes Toward Training ......

Interaction and Participation

Technology Evaluations

VTT Course Conversion

Recommendations

References

Appendix A-Celestial Navigation Student Questionnaire

Appendix B-Picture-in-Picture Questionnaire

B- 0

Appendix C-Electronic Presentation Program Questionnaire

C-0

Appendix D-Student Groups and Performance Summary Tables

D-0

Appendix E-Summary Tables for Open-Ended Questionnaire Items

Appendix F-Interaction Tally Summary Statistics F-0 Distribution List 


\section{List of Figures}

1. Example of revised instuctor slide for small-print nautical publication ......................... 8

2. Picture-in-Picture (PIP) display of strip form and instructor......................................... 11

3. Average percent correct for student homework and final examination performance, and percentage of students passing the course..................................... 13

4. Type of student prior experience in performing celestial navigation computations

5. Student questionnaire ratings for instructors and learning activities (items 1-13)

6. Student questionnaire ratings for training aids and interaction (items 14-26)

7. Student questionnaire ratings for course overall and videoteletraining (items 27-30 and 34-37)

8. Students responses on how VTT affected opportunities to interact with the instructor (item 40)

9. Student responses on who most frequently provided assistance outside of regular class hours (item 38)

10. Student preferences for a method of instruction and willingness to participate in another VTT class

11. Interaction tally results for instructor and student questions in terms of

(a) interactions per hour, and (b) interactions per hour per student

12. Instructor reminders per hour to local site students to use microphones

13. Picture-in-picture questionnaire rating responses

14. Picture-in-picture questionnaire responses for effectiveness and preference 


\section{Introduction}

\section{Problem}

Many Navy personnel who must receive training are geographically separated from training resources. An increasingly efficient approach to meeting this requirement is needed as the Navy downsizes and training resources become constrained. Videoteletraining (VTT) has been found to be an efficient and cost beneficial way to address this issue because it enables a single instructor to teach multiple classes that are at different remote geographic locations. The Chief of Naval Education and Training (CNET) now has VTT in operational use in the CNET Electronic Schoolhouse Network (CESN). This VTT system utilizes an interactive two-way video and audio television system that allows distant remote site students to participate in the instruction originating from a local site where other students are co-located with the instructor.

VTT has generally been used for the delivery of lecture-based instruction. Even with current VTT technology, there is some reduction in the quality of the audio and video as compared to live instruction; e.g., it reduces the visibility of personnel at different classroom locations and also reduces the ability of instructors and students to interact as they do in a traditional classroom. These constraints make it more difficult to conduct training which is not instructor centered, such as a variety of courses with hands-on laboratories and learning environments that are highly interactive. Significant travel or instructor costs could be avoided if such training could be delivered via VTT rather than in traditional classrooms. A course in Celestial Navigation presented challenges for conversion to the VTT format because it contained several aspects that departed from those found in the typical lecture-based course. The course uses various visuals with detailed print from tables, contains hands-on laboratories involving difficult computations and plotting, and there is a concern for assisting remote site students in resolving problems with computations.

\section{Objective}

The objective of this research was to evaluate the feasibility of delivering a Celestial Navigation refresher course by video teletraining (VTT) in terms of the effects of VTT on student performance, student attitudes toward the training, and instructor-student interaction.

\section{Background}

Previous research and development work has demonstrated that VTT can be an efficient and cost beneficial method to electronically deliver training to remote Navy personnel (Bailey, Sheppe, Hodak, Kruger, \& Smith, 1989; Rupinski \& Stoloff, 1990; Rupinski, 1991; Simpson, Pugh, \& Parchman, 1990, 1991a, 1991b, 1992, 1993; Stoloff, 1991; Wetzel, Radtke, \& Stern, 1993, 1994). Prior research on instructional television also indicates that student achievement is not affected and that any initial unfavorable attitudes lessen as a result of experience with the medium (Wetzel, et al., 1993, 1994). The major cost benefits of video teletraining systems appear to be seen in circumstances where travel, per diem, or duplicated instructor costs are avoided by usage that is intense enough to offset the costs of the technology. Courses that are particularly beneficial in reducing travel costs are those with a high student throughput and which are short in duration (a week or less). Cost and efficiency benefits have resulted from use of the VTT system implemented in the CESN. Historical cost data developed by the CESN from 1989 through 1994 indicate that 
the system reaches the break-even point approximately half way through a year (i.e., VTT system costs are approximately half the travel and training costs that are estimated to have been avoided).

The possibility of using VTT for a wider range of courses would extend the cost and efficiency benefits of VTT beyond the lecture-based courses that are typically delivered by VTT. This issue has been addressed by experimentally developing training strategies and evaluating technologies as part of the Distributed Training Technology (DTT) project. The purpose of this project is to extend the utility of VTT to courses which present difficulties for this instructional medium, such as those courses with hands-on laboratories. The present study extends other work on adapting instructional content which presents challenges for delivery by VTT. Prior work in this area with Navy courses includes the hands-on laboratories in a Damage Control Petty Officer course (Simpson, et al, 1992), leadership training involving small group processes (Simpson, Wetzel, \& Pugh, 1995; Wetzel, Simpson, \& Seymour, 1995), and general guidelines for converting courses to VTT (Simpson, 1993). Other in-progress work to be reported later includes hands-on laboratories in a Fiber Optic Cable Repair course and the use of computers in a Quality Assurance course.

The Celestial Navigation course differs somewhat from traditional lecture-based courses in several ways that made it more difficult to convert to VTT. Although much of the course is instructor-centered and involves lectures, there is also a significant computational component of the course that contains materials and activities that depart from the typical lecture based course. There were several concerns about the feasibility of delivering the course when it was being considered for VTT during the time that the San Diego CESN was being brought on-line at the Fleet Training Center (FTC). The course is a difficult refresher course that assumes some prior knowledge of the content. Nautical publications with numerous small print tables are shown by the instructor on an overhead projector which supports a resolution greater than that obtained with video. Relative to other Navy laboratory courses with more substantial equipment and activities, the Celestial Navigation course could be said to involve a mild form of a hands-on laboratory. These hands-on student laboratories involve the use of four publications to perform computations and various small items of equipment, such as used for plotting on charts.

Several adaptations were developed to allow the course to go on-line as a VTT course that went beyond the typical need to convert overhead projector slides. For example, problems with showing detailed small print in publications were circumvented by developing special inserted graphics, and plastic overlays were developed so that plotting work could be scored by facilitators at remote sites. Students can show an instructor their work and resolve difficulties that arise with their computations in a traditional classroom where the instructor is physically present. The interactive nature of the aid provided to students by instructors in traditional laboratories is more difficult to provide to remote site students who are accompanied only by the VTT facilitator or other students. Subject-matter expertise is not a requirement for VTT facilitators, whose duties are to maintain the remote classroom, operate equipment, distribute materials, and score tests. Thus, it was of concern whether remote students would be able to get help in performing computations when the instructor could not circulate among students and look over their shoulders in the interactive way that traditional laboratories permit.

It was also of interest whether several technologies could be employed to assist in delivering the course. A significant portion of the course involves the instructor working through a series of computational steps that are written on a "strip form" template that is shown to the class. During 
these periods the VTT instructor can spend a good deal of time off-camera when writing on strip forms or displaying graphics which must be shown from a video document camera on the podium. An alternative to this single view was introduced by using picture-in-picture (PIP) technology and a robot tracking camera to allow a combined view of both the strip form and the instructor to be shown simultaneously. A questionnaire was employed to assess whether students found this technology useful. Another questionnaire was used to assess any preference for an electronic presentation program that was adapted to show a strip form in one of the instructor's lessons.

The primary issues in evaluating the feasibility of the VTT version of the Celestial Navigation course were as follows: (a) how well do remote-site students perform academically in the course compared with students who are in a classroom with the instructor, (b) what effect did the VTT medium have on student acceptance and attitudes, (c) what effect did VTT have on the level of interaction and participation for remote students compared with those at the local site, and (d) what practical efforts were required to deliver the VTT course that provide lessons learned applicable to other courses (e.g., conversion of materials to a form suitable to VTT).

\section{Method}

The overall plan for the evaluation study, treatment groups, outcome measures, and a description of the course and the methods used to convert the course are described below. The outcomes of interest were a comparison of student grades, student evaluations of the training, and the level of instructor-student interaction in VTT classes.

\section{Treatment Groups}

A single independent variable (type of instruction) with three states was used. This variable consisted of three treatment groups: (1) students in a traditional classroom with an instructor; (2) a VTT local classroom where students were also with an instructor, and (3) VTT remote classrooms where students were connected to the local classroom by a fully interactive two-way audio and two-way video VTT system. A subsample of students were also included in an evaluation of picture-in-picture (PIP) technology and the use of an electronic presentation program described later.

\section{Outcome Measures}

Dependent variables (outcome measures to assess the effect of the independent variable) were in three general categories: student perceptions of VTT and training quality, student academic performance, and instructor-student interaction. Each of these variables was defined in terms of the measures described below and data were gathered with the data collection instruments in Appendices A, B, and C.

\section{Student Performance}

Three aspects of student performance were examined: (1) homework percentage correct, (2) final examination percentage correct, and (3) percentage of students passing the course. Student performance in this course is assessed on two types of work: in-class assigned work problems and a practical final examination. The criterion for passing the Celestial Navigation course is 75 
percent for both the assigned work and the final examination. If either of these is below 75 percent, the student does not pass the course.

Assigned homework during the week is generally performed in periods allotted during class, after class, or performed off site. The percentage correct over 13 of these exercises is averaged for the homework portion of the course grade. The final examination consists of a lengthy problem scenario that takes approximately five hours to complete. The students begin the problem on the afternoon of the fourth day and complete the examination on the final, fifth day.

\section{Student Questionnaire}

A 44 item questionnaire was developed for the Celestial Navigation course (see Appendix A). The questions were organized in terms of the following categories: (1) instructors, (2) learning \& classroom activities, (3) training aids, (4) interaction/participation, (5) overall course rating, (6) background and prior experience with the course material, (7) video-teletraining, and (8) open ended questions soliciting comments on VTT, likes and dislikes about the course, and suggestions for improvements. Most of the questions (34 items) used a rating format where agreement or disagreement with a statement was rated on a five point scale ordered as follows: [1] Strongly Disagree, [2] Disagree, [3] Neither Agree/Disagree, [4] Agree, [5] Strongly Agree. The remaining questions consisted of six multiple choice items, a five-point rating item on the pace of the course, and four open ended questions, one of which was a second part of a multiple-choice item.

There were two versions of the questionnaire, one for VTT classes (44 items) and one for traditional classes ( 38 items). The 38 item questionnaire for the traditional classes used the same items as the 44 item questionnaire except that six items were omitted because they related to VTT and could not be answere by the traditional classes (items 34-37 and 40-41). Items 38 and 39 were slightly modified to allow administration in the traditional classes. Item 38 did not have "facilitator" as a choice for assistance provided to students, and item 39 was prefaced by a short paragraph describing VTT so students could answer which method of instruction they would prefer for the course.

\section{Interaction Tally}

An observer recorded the frequency of interaction among sites during the first three days of the course for six VTT class convenings. The interaction tally was recorded for interactions that occurred over the VTT network and involved recording the frequency of events in the categories given below. The observer recorded interactions from a separate room connected to the network and was not present in either the local or remote classroom. Interactions had to be related to course content and were recorded during lecture, but not laboratory sessions. Start and end times for each class period were recorded on the tally form in order to account for variations of these periods over different class convenings. For each of the first five categories below, a check mark was entered in a box corresponding to whether it occurred at the local site or each of the remote sites.

1. Instructor Question Open to Any Site: Instructor asks a question (and receives an answer) in which no site is identified so that all sites are free to respond to the question. 
2. Instructor Question Names a Site: Instructor asks a question (and receives an answer) that identifies a site which should answer, either the local site, a specific remote site, or "any" remote site.

3. Instructor Questions Specific Student: Instructor asks a question (and receives an answer) directed at one student by singling out the student by name, title, or by pointing (a class roster for each site was created during the first morning of the class).

4. Student Initiated Question: A student initiates a question to the instructor, class, or another student.

5. Student Conversations and Exchanges: Student exchanges, comments, or general conversations involving continued back-and-forth exchanges on an issue, such as to resolve a problem. These were most commonly a continuation of a student initiated question that resulted in more than one communication each for the instructor and student, including a student other than the one initiating the question.

Several other miscellaneous circumstances were recorded separately in addition to the above categories. Categories 6 and 7 were recorded for the whole class and not by remote and local sites. Category 8 was recorded only for local students.

6. No Answer to Question: There was no answer from students to an instructor question which was specific to the instructional content.

7. No Answer to Generic Request for Questions: The instructor asked in one way or another if there were "any questions" and no response was received from the students. These questions were generic queries that were used to pause before proceeding with the instruction.

8. Reminders to Local Students to Use Microphones: The instructor reminded the local San Diego site to use the push-to-talk microphones so remote sites could hear questions and comments.

\section{Subjects and Classes Observed}

VTT classrooms were at three locations: the originating or VTT local site at the Fleet Training Center (FTC) in San Diego, CA, and two VTT remote sites located at the FTC Detachment at Treasure Island, CA, and at the Trident Training Facility (TRITRAFAC) at Bangor, WA. Traditional classes were conducted at the FTC in San Diego in a conventional non-VTT classroom designed for the Celestial Navigation course.

Student grades were compared for a sample of 279 total students who received similar training materials. These students were drawn from nine convenings of the VTT class (135 local and 66 remote students) and from five convenings of the traditional class (78 students) conducted during the same time periods as the VTT classes. Of the nine VTT classes, Treasure Island was a remote site nine times and Bangor was a remote site five times. For the classes studied, the average class size was 15.0 students for VTT local, 7.3 for VTT remote, and 15.6 for the traditional classes. An additional set of archival student grades was examined for 91 students in another five traditional 
classes that had used somewhat different instructional materials prior to the time that the course had been converted to VTT.

A subset of the total sample of 279 students completed questionnaires and were observed to record the interaction tally. Questionnaires were completed in nine VTT class convenings (128 VTT local and 61 VTT remote students) and in three traditional class convenings (52 students). Interaction tallies were recorded by observers for six of the VTT classes (the local site was connected with two VTT remote sites for three convenings and with only one remote site during the other three convenings).

All students were enrolled in normally scheduled class convenings. The typical officer student was a Lieutenant Junior Grade or Lieutenant (84\% of all officers were O-2 and O-3). The typical enlisted student was in the Quartermaster rating and was a Third, Second or First Class Petty Officer ( $82 \%$ of all enlisted were E-4 to E-6). As discussed later, the enrollment pattern of the intact groups examined here resulted in relatively more enlisted than officer students at remote sites compared to the local site. Remote site students were also slightly more junior than those at the local site. The number of students per group, average rank, and the period of the study are given in Table D-1 of Appendix D.

One instructor taught about three fourths of the class sessions during the study and the remainder of the sessions were taught by one or two other instructors. The primary instructor for VTT classes had previously taught the course in the traditional manner (i.e., prior traditional classes identified in Appendix D). Three students in the study later became instructors themselves and taught portions of later classes.

\section{VTT Course Preparation}

\section{Description of Course}

The five day Celestial Navigation refresher course studied was taught at the Fleet Training Center in San Diego (Course Identification Number J-061-0603). There are typically 15 to 18 students per class. A maximum of 24 students can be accommodated within the VTT classroom. The course consists of lectures and practical application computational exercises. These encompass celestial navigation theory, time, sunrise and sunset, moonrise and moonset, star-finder, sextant correction, latitude by Polaris, local apparent noon, azimuths, and celestial computations using nautical and air almanacs and standard strip forms (vertical forms used to enter a sequence of computations). Students are officers supervising or assigned to navigational duties and enlisted Quartermasters (QM) filling a billet as a leading QM. The course is a refresher course and assumes prior knowledge or practical experience in performing the celestial navigation computations.

The course involves lecture and laboratory sessions over the first four days. Laboratory sessions involve practical experience in performing computations and some plotting. Some laboratories are interspersed among lectures during the day, and the first three days end with a two hour laboratory session to complete the days assigned homework, some of which is often performed later off-site. A lengthy final examination begins on the afternoon of the fourth day and continues through midday of the final fifth day of the course. A 42 minute film or videotape is shown twice: early on first day of instruction and again during the fourth day. The film covers 
celestial navigation concepts as part of the "theory" portion of the course. It uses limited animation and includes color drawings of the relation of the earth, heavenly bodies, and various projected lines and angles. Students use four navigation publications and a variety small navigational equipment.

\section{VTT Course Conversion}

Converting the Celestial Navigation course to VTT required efforts that exceeded those usually required to convert a typical lecture-based course. For example, remote sites had to be outfitted with numerous materials and equipment for use in student laboratories, there were many visuals with small print in tables that required special attention, and a method had to be devised to allow student plotting to be scored at remote sites.

The following equipment and supplies were procured to outfit the two remote sites: (1) four publications (two navigation handbooks and two nautical almanacs consisting of tables); (2) parallel rulers were used in lieu of drafting machines used in the traditional course; (3) star finders; (4) circular nautical slide rules; (5) drafting dividers; and (6) blank plotting charts.

A number of paper items had to be duplicated for remote sites. These included homework sheets and strip forms for 13 exercises, and various other handouts. A daily schedule of events was developed so that remote site facilitators could distribute materials to students at the appropriate time. Remote site personnel were required to maintain secure copies of the final examination to avoid test compromise.

There were a substantial number of transparencies shown by the instructor in the traditional class. Many of these transparencies displayed tables containing small print and were shown on an overhead projector with a higher resolution than is supported by video. These graphics are used for orientation purposes so that students can locate entries in their own copy of the relevant publication, such as which page is currently being used, various row and column headings, and the relevant entries within the table on that page. Figure 1 illustrates a sample graphic using a technique developed to overcome the difficulty with showing the small print in the tables used in the course. The critical portions of the text have been placed within "bubbles" containing enlarged text and arrows point to where that entry is located on the page (stick-on labels with darkened edges were easily adapted for this purpose). Because the print is normally very small, the bubbles directed student attention to the relevant entries that were large enough to read. The strip forms were also enlarged and segmented into several pages because these vertical forms can be as long as a typewritten page and cannot be seen in their entirety over a video system (an example is shown later in Figure 2).

Transparencies were converted to a paper-based form so that they could be presented on the video document camera stand. A landscape orientation was used for visuals as appropriate to the 3:4 aspect ratio of television. The resolution supported by video required that the visuals be converted to contain fewer lines and words (pages with about 15 lines and 25-30 characters per line are typically recommended). A similar relative size of the visuals on a page was maintained so that readjustments of the zoom lens on the document stand would be minimized as the instructor moved through the slides. 


\section{PAGE 274}

POLARIS (POLE STAR) TABLES, 1993

FOR DETERMINING LATITUDE FROM SEXTANT ALTITUDE AND FOR AZIMUTH

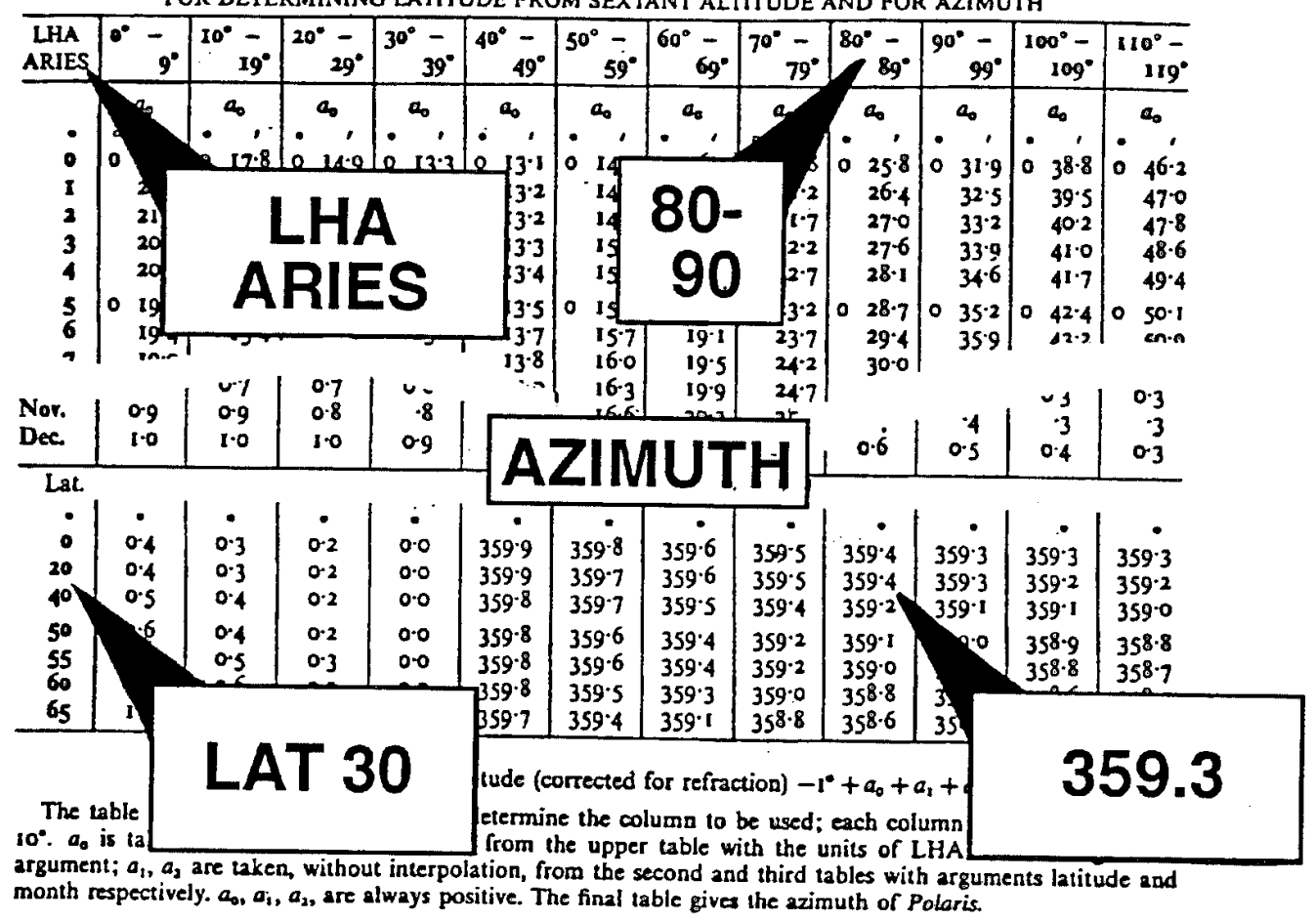

Figure 1. Example of revised instructor slide for small-print nautical publications.

An unfortunate side effect of converting the course to VTT was that the computational problems themselves had to be updated. The previous problems were based on a prior year of the nautical almanac which could no longer be purchased for each student at the two remote sites. Consequently new computational problems for the current year were developed based on new almanacs purchased for all sites.

The 42 minute $16 \mathrm{~mm}$ film used in the course was professionally converted to videotape form. The quality of the film was not materially affected and was adequate when viewed via the digitally compressed video of the VTT system.

Remote site facilitators scored student final examinations using new scoring methods designed to captured the expertise of the instructors. An answer key for the numeric entries on the test form was easily prepared, but the plotting portion of the test was more problematic. An acetate overlay was developed for the facilitators to place over a student's plotting chart. The overlay was marked with the correct course, "fixes," and labeling required of students. Remote site facilitators for the initial VTT class received training from the instructors on the course procedures during a visit to San Diego. 


\section{VTT Classroom Configuration}

The training sites were equipped with a fully interactive two-way video and two-way audio digital VTT system. Digital video was transmitted over terrestrial T1 lines at $384 \mathrm{Kbps}$ using a VTEL brand 386 MediaMax Codec and Multipoint Control Unit. The classrooms were equipped with a minimum of three video cameras that could be selected by a handheld remote or from a control panel at the rear of the room. One video camera on the rear wall showed a view of the instructor and another pan/tilt video camera on the front wall to showed a view of the students. An instructor podium at the front of the room was equipped with an Elmo brand video document camera used to show hardcopy visual materials. The instructor could view a small monitor below a glass top on the podium when positioning graphic material on the video document camera. The classrooms were not equipped with chalkboards or whiteboards. All students viewed 40-60" TV monitors to see the instructional materials shown on the video document camera.

Remote site students viewed all instruction on large 40" TV monitors. Local site students who were physically present with the instructor viewed only the instructional materials or remote site students on the monitors. The televised version of the class viewed by remote site students alternated between a view of the instructor, the printed materials shown on the document camera stand, and occasionally a view of the local students. Two large color monitors were located at the front of the room, usually near the center for remote students and to the side in each corner for local students. Remote sites were typically configured so that one front monitor showed the incoming video and the other showed the outgoing video. Two monitors in the back of the room allowed the instructor to view the outgoing video and the incoming video from the remote site that had most recently spoken.

Students at all sites could hear each other by using a push-to-talk microphone that was shared by each pair of students. Push-to-talk microphones were used in order to reduce extraneous noise, such as from private conversations, shuffling of papers, or moving books. Pressing a microphone had the effect of switching the video to a view of the site using the microphone. Students were instructed in the use of the VTT system on the first day of class. Students in the local classroom were reminded to use the microphones so that remote sites could hear them.

The VTT classrooms accommodated a maximum of 24 students in three rows of tables facing the front of the room. The arrangement of the rooms varied somewhat from site to site. The local San Diego classroom was equipped with 12 tables with a short depth ( 24 X 60"). An aisle down the middle of the room separated the tables, each of which was shared by a pair of students. Remote classrooms had somewhat bigger tables during the study and contained fewer students so that there was more room to spread out student materials.

Each remote classroom was monitored by a facilitator who was not a subject-matter expert in the course content. The facilitator was responsible for the operation of the equipment from the rear of the classroom, maintaining order, class rosters, distributing and collecting class materials, and scoring the homework and final examination. 


\section{Technology Evaluation Questionnaires}

Two small evaluations of new technologies introduced into the course were conducted with a subsample of the students described in the main study. The value of using two technologies was evaluated: Picture-in-Picture views and an electronic presentation program.

\section{Picture-in-Picture Evaluation}

The objective of this evaluation was to assess the desirability of enhancing an instructor's presentation with Picture-in-Picture (PIP) technology during lectures where the instructor's visuals are shown extensively. The main video image of an instructor's visual aids was accompanied by a smaller inset PIP panel which showed a view of the instructor. The visual aids shown during VTT classes are presented on a video document camera or copy stand and consist of word displays, tables, drawings, pictures, and writings or drawings performed by the instructor during a class session. The use of PIP allowed a view of both the instructor and his visuals to be seen simultaneously instead of just one view or the other. This technique allows the instructor to maintain a continuous visual presence instead of only being heard from off screen while the visuals are shown. However, this technique could be detrimental if the PIP image were allowed to overlay portions of the visual aids so students cannot see relevant information, or if the PIP image of the instructor distracted students from observing relevant information in the visual aids.

Figure 2 depicts the screen layout that was employed by using a Panasonic WJ-MX30 video mixer to create the PIP image as a vertical panel. A strip form being written on by the instructor is shown on the left and the instructor is shown from the waist up on the right of the screen. The PIP image was consistent with the vertical orientation of the strip forms being used and was approximately $30 \%$ of the horizontal width of the screen. A ParkerVision "CameraMan" robot tracking device was used to keep the image of the instructor at the podium centered in the PIP window. This device tracks the instructor by following a pair of infrared lapel targets worn on the front and back of the instructor. The pan and tilt of the camera is continuously adjusted to track the lapel targets as the instructor moves. The tracking typically involves small left or right movements and a constant offset setting allows the view of the instructor to be positioned in a predefined region of the video screen.

The evaluation design involved presenting periods of instruction with PIP alternately enabled or disabled, or with PIP continuously enabled. Students then completed a questionnaire on the value of the PIP technique and their preference for its use. Three groups of students were employed in the evaluation. Two groups of students received alternating periods of instruction during which PIP was either enabled or disabled. This "Alternating PIP" treatment was given to 37 VTT local and 15 remote students during two class convenings. An additional group of 17 VTT remote students were in a "Regular PIP Use" condition during three class convenings when the PIP was used throughout the week. 


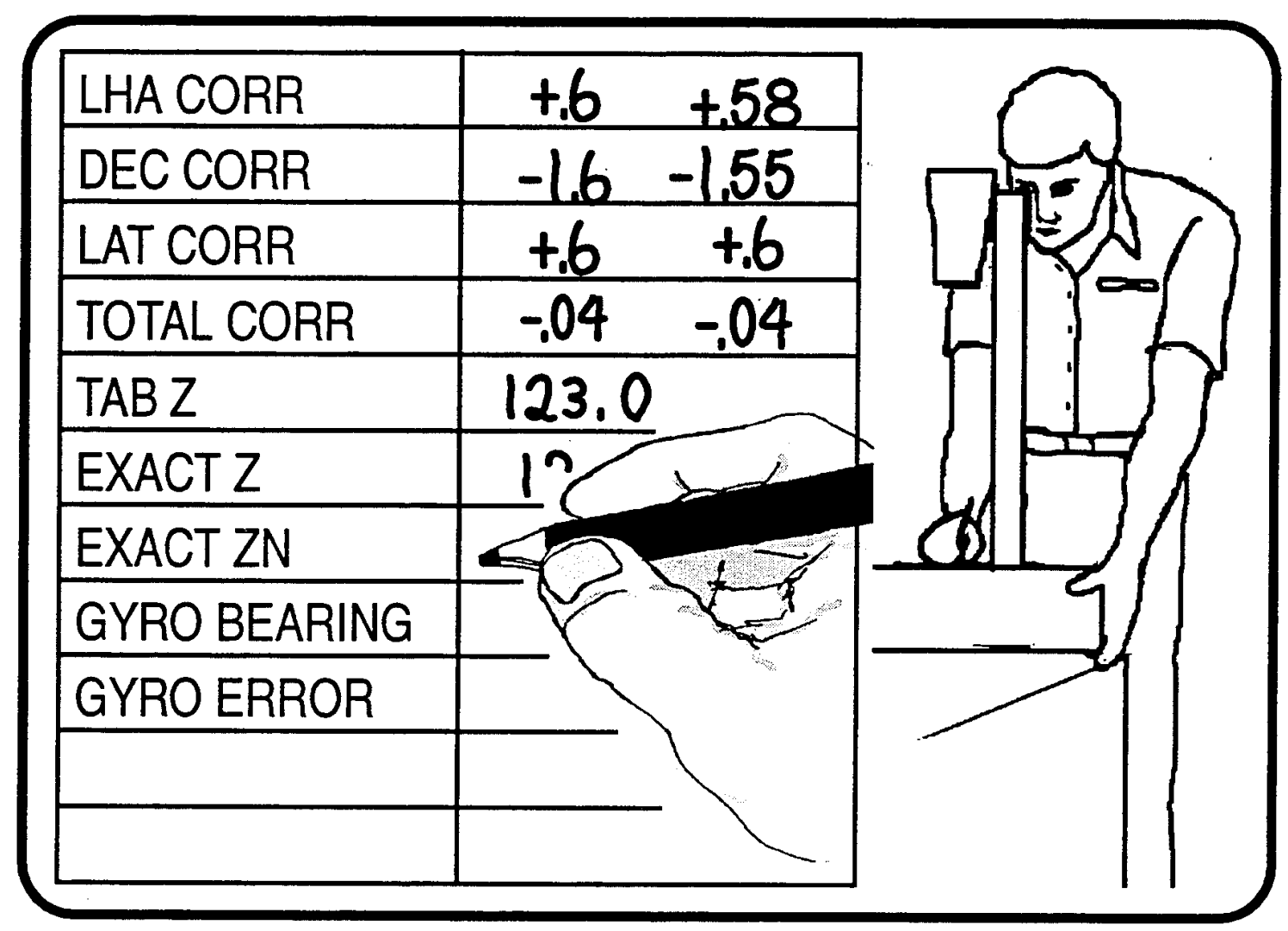

Figure 2. Picture-in-Picture (PIP) display of strip form and instructor.

The alternating PIP treatment conditions were given to students according to a scheme that balanced the order and exposure time of the PIP and non-PIP periods of instruction. The order of the conditions was balanced over two class convenings by rotating the conditions over the morning and afternoon periods of the first two days of the classes. During the first class convening, the sequence on the first day involved using PIP during the morning (PIP) and not using PIP in the afternoon (No-PIP), and on the second day the morning was No-PIP and in the afternoon was PIP. During the second class convening, the sequence on the first day was No-PIP in the morning, PIP in the afternoon, and on the second day PIP in the morning and No-PIP in the afternoon. During periods when PIP was not used the full screen showed only the visuals or strip form and the instructor did not appear in the right hand portion of the screen. The tracking camera was used during both PIP and non-PIP presentations for all treatment groups.

A simple verbal announcement was given on the morning of the first day of the class that PIP would be used during some class periods and not others and that a brief evaluation questionnaire would be given later. The 11 item PIP evaluation questionnaire given in Appendix B contained 10 items rated on a five point strongly-agree to strongly-disagree scale and one two-choice item. Students in the alternating PIP groups completed the PIP questionnaire at the end of the second day of the course. 
The PIP technique was implemented on a regular basis in the course following the data collection with the alternating PIP conditions. When used as a regular feature throughout the course, the PIP was only shown on the outgoing video to the remote students and was not shown on the monitors for local students who could see the instructor directly in the classroom. A total of 17 students who received PIP on a regular basis were administered questionnaires on the final day of the course during three additional class convenings.

\section{Electronic Presentation Program Evaluation}

A computerized slide presentation program was used to present one of the celestial navigation lessons that used strip forms. A General Parametrics Corporation VideoShow device was used for this lesson, although any of several other manufacturers' software program could have been employed in conjunction with a computer-to-video scan converter. The program was used to present an electronic version of a strip form which serially revealed each of the entries that the instructor would have normally written as the computations on the strip form were performed.

A short five item questionnaire was administered to students that asked them to compare the electronic presentation program lesson with the conventional hand written method used in other lessons (see Appendix C). The same five point agree-disagree rating scale used in the celestial navigation student questionnaire was used for four of the items. Two items asked for a rating of the effectiveness of the hand-written and electronic methods respectively. Two items asked for a rating on the readability of the text with the two methods respectively. One item offered a two-alternative choice between the two methods. The questionnaire was completed by 15 VTT local students and 8 VTT remote students during one class convening.

\section{Results}

Traditional, VTT local, and VTT remote treatment conditions are compared below in terms of student performance in the course, student responses on the post-course questionnaire, participation patterns from the interaction tally, and student responses on technology questionnaires. The number of cases used for the analyses varied slightly over these different outcome measures (cf. Appendix D). The most important comparisons in this data are between the two VTT groups because they attended exactly the same classes, whereas the traditional students attended separately convened classes.

\section{Student Performance}

Student performance in the course was assessed in terms of three measures: average percentage correct on assigned work (homework) during the week, percent correct on the final examination, and the proportion of students passing the course. Figure 3 shows these measures of performance separately for officer and enlisted students (additional detailed breakdowns of the results are given in Appendix D, Tables D-2, D-3, and D-4). ${ }^{1}$ Scores for 279 students were analyzed, consisting of

\footnotetext{
${ }^{1}$ Student performance was also examined archivally for an additional five traditional classes convened prior to converting the course to VTT. These classes were not included in the analyses reported here because the level of performance differed from traditional classes that occurred after course materials were converted for VTT. Tables in Appendix $D$ show that final examination performance and the percentage of students passing was much lower in these prior classes, possibly because the examination content was more difficult.
} 
140 officer students (48 traditional, 76 VTT local, and 16 VTT remote), and 139 enlisted students (30 traditional, 59 VTT local, and 50 VTT remote).

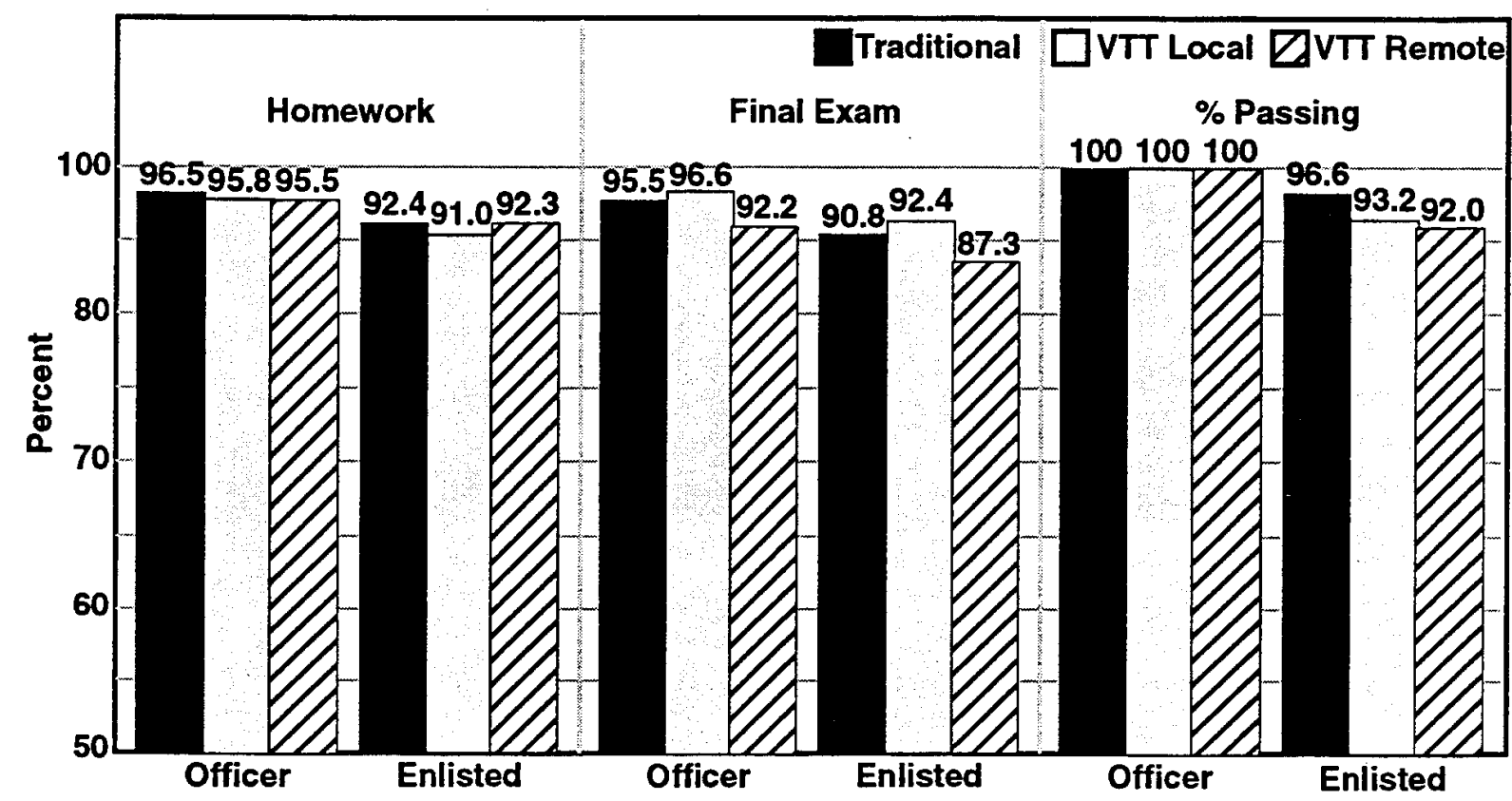

Figure 3. Average percent correct for student homework and final examination performance, and percentage of students passing the course.

The analyses of student performance were performed with each of the three treatment groups subdivided into officer and enlisted student subgroups. This approach was necessitated because the level of performance by officer and enlisted students differed and there was an unequal distribution of these students in the three treatment groups. Enlisted students were much more likely to appear at remote sites than were officer students (75\% of remote site students were enlisted, whereas $44 \%$ of local and $38 \%$ of traditional site students were enlisted). Over all treatment groups combined, officer students performed at a slightly higher level than did enlisted students (4.2\% higher on homework and 5.5\% higher on the final examination). Thus, the officer-enlisted subdivision of treatment groups avoids the comparison of a more equal mix of students at the local site with remote sites that primarily contained enlisted students that scored slightly lower regardless of site.

A two-way analysis of variance (ANOVA) design with two between-subject factors was employed to test statistical significance with the homework and final examination scores. The first factor consisted of the three treatment groups (traditional, VTT local, and VTT remote), and second factor subdivided these groups into officer and enlisted groups. This analysis provides a main effect test of significance for each of the two factors and a test of whether the two factors interacted as a function of particular levels of the factors. The number of students passing the course was evaluated by a test of proportions expressed as Chi Square (Fleiss, 1981, p.139). 


\section{Homework}

The average percent correct for the 13 homework exercises during the week is shown in the left hand panel of Figure 3. There were only negligible differences between treatment groups. The largest group difference was only $1.4 \%$ within the enlisted groups. Officers scored from $3.2 \%$ to $4.8 \%$ higher than enlisted students. The only significant effect revealed by an analysis of variance was a main effect difference between officer and enlisted students, $F(1,273)=25.81, p<.01$. The main effect for the three treatment groups was not significant, $F(2,273)=0.72, p>.05$. The interaction effect was not significant, $F(2,273)=0.36, p>.05$, indicating a similar pattern among treatment groups for both officer and enlisted students.

\section{Final Examination}

The average percent correct on the final examination is shown in the middle panel of Figure 3 . The highest performance was found with VTT local students, followed closely by traditional students, and the lowest performance was with the VTT remote students. The largest difference obtained was between the two VTT groups, where VTT remote was lower than VTT local by $4.4 \%$ for officers and $5.1 \%$ for enlisted students. An analysis of variance indicated significant differences for the treatment groups main effect $F(2,272)=6.85, p<.01$, and for the officer-enlisted groups main effect $F(1,272)=19.34, p<.01$. The interaction effect was not significant, $F(2,272)=0.05$, $p>.05$, indicating that the same pattern among treatment groups was found among both officer and enlisted students. Tukey HSD tests indicated that the VTT remote group was significantly lower $(p$ $<.01)$ than VTT local and traditional groups, which did not differ significantly from one another.

An alternative analysis approach that could be substituted for that given above would be to control for the effect of differing student characteristics that resulted from nonrandom enrollment pattern among the sites. In addition to there being an inequity in the number of officer and enlisted students among the sites, remote students were also slightly more junior than those at local sites (Table D-1 in Appendix D). Final examination scores were correlated 0.33 with officer-enlisted status and 0.22 with increasing military experience (expressed as Z-score military rank within each officer and enlisted group). An analysis of covariance (ANCOVA) used these two student attributes as covariates to adjust the treatment group scores for the different mix of these student characteristics. The ANCOVA also showed the three treatment groups to be significantly different, $F(2,273)=5.62, \quad p<.01$. Based on this analysis, the adjusted group means are $93.1 \%$ for traditional, $94.3 \%$ for VTT local, and $90.3 \%$ for VTT remote. The local and remote groups differ by only $4.0 \%$ when officer-enlisted and military seniority are controlled, and would differ by $4.8 \%$ if only officer-enlisted status were controlled (Table D-3 in Appendix D). Thus, remote site student performance appears somewhat higher when adjusted for inequities in student characteristics that varied with the pattern of enrollment among the sites.

\section{Percent Passing Course}

The percentage of students passing the course is shown in the right hand panel of Figure 3. Students passed the course if the homework and final examination percentages were both $75 \%$ or more, and failed if either score was below this criterion. All officer students passed the course in all three treatment groups. The percent of enlisted students passing was similar among the three groups, which differed by $4.6 \%$ at most. A slightly higher rate of passing was shown by traditional students $(96.6 \%)$ than either of the two VTT groups. The VTT local (93.2\%) group passed the 
course at nearly the same level as the VTT Remote $(92.0 \%)$ group. In terms of actual frequencies, the number of enlisted students who did not pass the course was 1 of 30 for traditional, 4 of 59 for VTT local, and 4 of 50 for VTT remote.

Whereas all officer students passed in all three treatment groups, only the enlisted student data were evaluated with a test of the proportion passing (Fleiss, 1981, p.139). The proportion of students passing in the three groups did not differ significantly $\left(\chi^{2}(2)=0.69, p<.05\right)$.

\section{Discussion of Performance}

Taken together, student performance was generally at a high level over the three performance measures. There were no significant differences between the treatment groups for the homework and the percentage of students passing the course. Remote site students performed significantly lower on the final examination. However, the $4 \%$ to $5 \%$ lower performance on this examination was not large and did not significantly affect the number of students passing the course.

A potential explanation for part of the difference between groups on the final examination was offered by instructors. Informal observations suggested an occasional remote site student performed poorly due to poor plotting practices. A little over half of the examination points are awarded on the quality of the plotting itself and the use of standard conventions, such as whether and how labels have been written for the course, speed, fix, projected positions, lines of position, changes in course and speed, and the angle of the labels. If at least some of the difference between groups is on this portion of the examination, then it may reflect fewer opportunities for remote students to have been corrected by the instructor during the week, which is more readily accomplished at the local site when instructors circulate among students during laboratories involving plotting. If further monitoring of the course shows this explanation to be true, then it would be recommended that (1) corrective guidance could be given by the facilitator or redirected to the instructor by viewing remote student work on the video document camera, or (2) a training aid could be developed such as a handout showing examples of both errors and correct usages of the plotting standards.

\section{Student Questionnaire}

Student evaluations and perceptions of the training and VTT were measured with a post-course questionnaire (Appendix A) which contained a series of statements to be rated, multiple-choice questions, and open-ended questions. The questionnaire was completed by a total of 241 students (52 traditional, 128 VTT local, and 61 VTT remote). These students were drawn from five traditional and nine VTT class convenings. Students in the three treatment groups completed a common set of questionnaire items (1-33, and 38-39, 42-44). A subset of items that applied only to students in VTT classrooms were not included on the questionnaire given to traditional students (items 34-37 and 40-41).

\section{Student Prior Experience and Background}

Items 31-33 asked the students about their prior proficiency and type of experience in manually performing the celestial navigation computations, and their future use of the skills from the course.

Item 31 asked students to rate the statement "Before this course, I was proficient at manually performing the celestial navigation computations" on a five point scale: (1) strongly disagree, (2) 
disagree, (3) neither agree/disagree, (4) agree, and (5) strongly agree. Student responses were slightly below the midpoint of the scale, indicating slight disagreement with the statement. The averages for traditional, VTT local, and VTT remote were $2.54,2.46$ and 2.88, respectively. An analysis of variance showed no significant difference between these groups, $F(2,236)=2.31, p>$ .05. The correlations between responses to item 31 and student performance in the course were negligible (the Pearson correlation with percent correct on homework and the final examination were 0.072 and -0.013 , respectively, $\mathrm{df}=237, p>.05$ ).

Item 32 asked "I previously had experience in manually performing the celestial navigation computations in this course" and presented the following alternatives: (1) No; (2) Yes, on-the-job experience; (3) Yes, course work; (4) Yes, both on-the-job experience and course work; (5) Other (please explain). "No" responses to this question indicated that a similar number of students in the three treatment groups said they did not have prior experience (17\% traditional, $16 \%$ local, and $18 \%$ remote). A test of these proportions of "No" responses was not significant $\left(\chi^{2}(8)=0.16, p>\right.$ $.05)$ (Fleiss, 1981, p139). However, Figure 4 shows that there were differences in the pattern of responses of officers and enlisted students in the other response categories. While a substantial proportion of both groups had both on-the-job experience and course work, many more enlisted than officer students indicated only on-the-job experience, whereas many more officer than enlisted students indicated only course work. Combining the three "Yes" categories, $67.5 \%$ of the officers and $84.5 \%$ of the enlisted indicated prior experience in one or the other, or both, of the experience categories, a difference of $17 \%$.

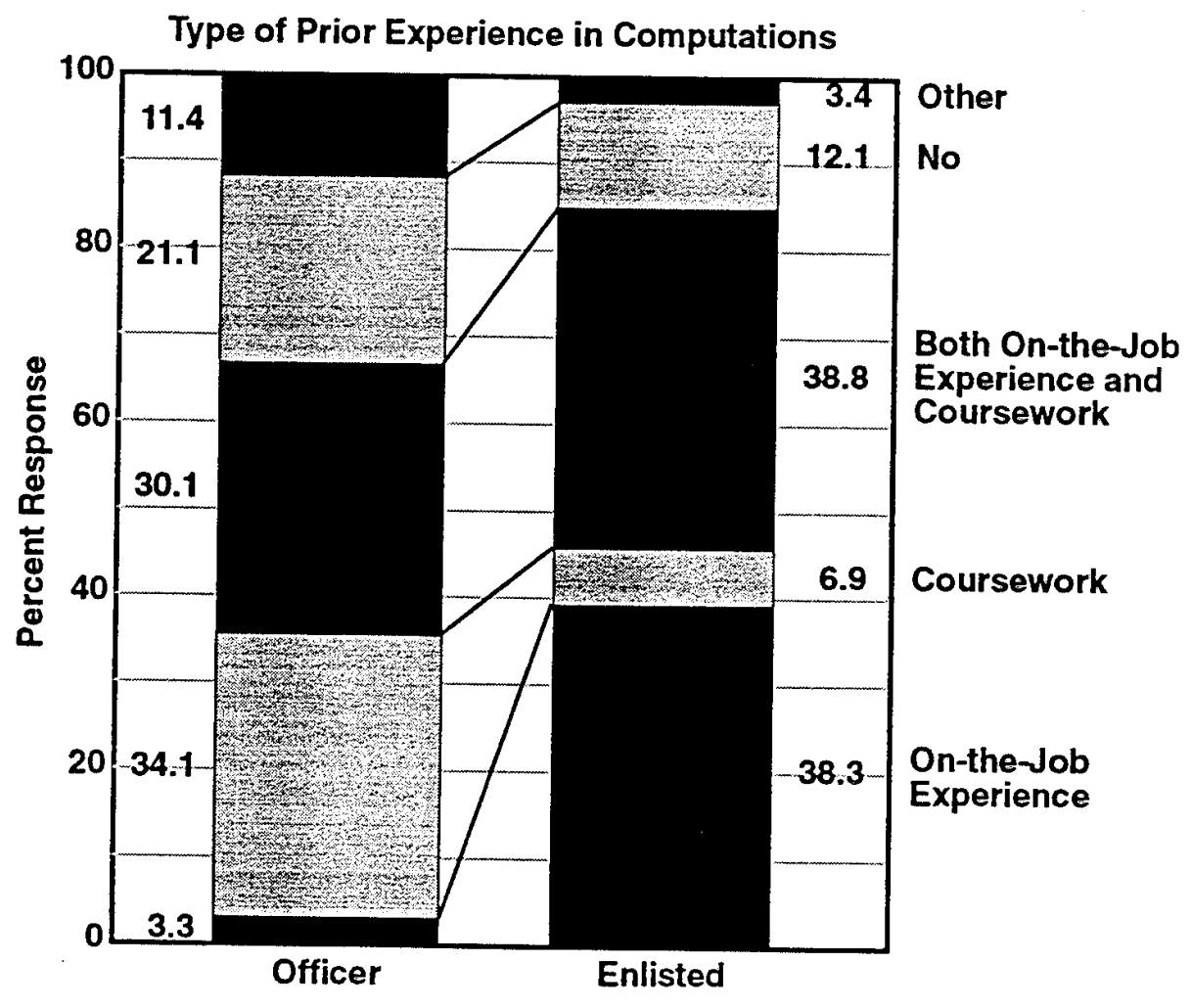

Figure 4. Type of student prior experience in performing celestial navigation computations. 
Item 33 assessed future use of the course content. The question asked "Will your duties or next assignment directly involve application of skills from this course" and presented the following alternatives: (1) No; (2) Yes, infrequently for shipboard duties; (3) Yes, routinely for shipboard duties; (4) The course was primarily for advancement purposes; (5) Other (please explain). A similar pattern of response was found for traditional, local, and remote sites and a Chi Square test showed no significant difference in the distribution of responses to these categories for the three groups $\left(\chi^{2}(8)=3.9, p>.05\right)$. The category "Yes, routinely for shipboard duties" was chosen by 77 , 77 , and 73 percent of the traditional, local and remote students. About three quarters of the officer (73.2\%) and enlisted (79.1) students indicated they would frequently use the skills from the course. Officers were slightly more likely to indicate that they would infrequently use the skills (22.8\%) than were enlisted students (8.7\%).

The responses to the three background questions $(31,32$, and 33) indicated that students generally had the prior experience required for this refresher course and were taking the course because of the direct application of the skills in their shipboard duties. The three treatment groups were similar in their prior experience and it was not related to their performance in the course.

\section{Student Ratings}

Statements rated by students were grouped in six categories: instructors, learning and classroom activities, training aids and materials, interaction/participation, overall course rating, and VTT (items 1-30, 34-37 in Appendix A). Statements were rated on a 5-point scale with a midpoint of 3 using the following scale values and labels: (1) strongly disagree, (2) disagree, (3) neither agree/disagree, (4) agree, and (5) strongly agree. Item 30 used a different rating scale as described below.

Figures 5, 6 and 7 show the mean ratings computed for traditional, VTT local and VTT remote classrooms. Most students gave positive ratings to the dimension being measured because the average rating for the positively phrased items was above the midpoint on the rating scale. However, there are some exceptions noted below that reflect implementation details or specific wordings in the questions. Many of the items show a trend where traditional and VTT local students respond similarly and VTT remote students give somewhat lower rating. This pattern is similar to that observed in previous VTT research (Simpson, et al., 1990, 1991a, 1991b, 1992, 1993, 1995; Wetzel, et al., 1995).

A one-way analysis of variance (ANOVA) was computed for each item to determine the statistical significance of rating differences among traditional, VTT local, and VTT remote classrooms. The degrees of freedom and $\mathrm{F}$ ratio results for these main effect tests are shown in the ANOVA T-L-R columns of Table 1. If a main effect was significant, Tukey HSD tests were also computed to examine which of the pairwise mean differences contributed significantly to the effect. Asterisks in the last three HSD columns of Table 1 indicate significant differences for the pairwise combinations among traditional (T), VTT local (L), and VTT remote (R) conditions, i.e., T-L, T-R, L-R. Most of the mean differences in Table 1 are small and many are statistically significant as a consequence of the relatively large sample sizes (mean differences significant at the .05 level are discussed below). 


\section{Question}

\section{- Instructors}

1. Instructors presented lessons clearly

2. Instructors encouraged class participation

3. Instructors answered student questions adequately

4. Instructors could be seen clearly

5. Instructors could be heard adequately

6. Instructors helped students who needed assistance

\section{- Learning \& Classroom Activities}

7. Concepts or theory underlying the computations were adequately presented

8. Computational procedures were adequately presented

9. I hesitated to ask questions in order to clarify concepts or steps in the computations

10. I received help on computational problems when I needed it

11. I had access to the classroom when class was not in session

12. I had access to instructors outside of class

13. Assigned problems were graded to provide feedback
Disagree Agree
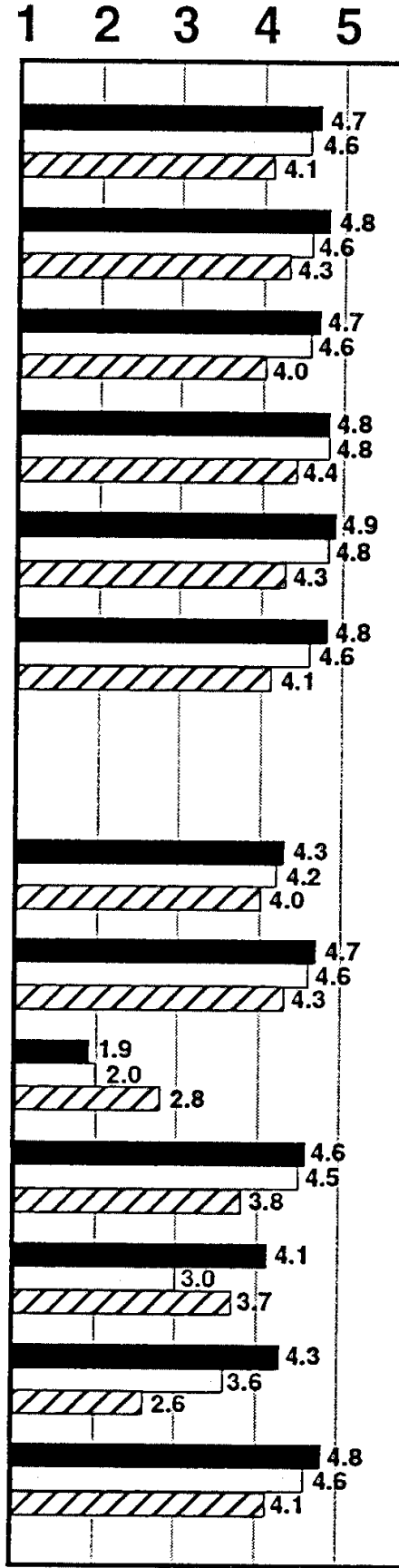

Traditional

VTT Local

Z7VTT Remote

Figure 5. Student questionnaire ratings for instructors and learning activities (items 1-13). 


\section{Question}

\section{- Training Aids/Materials}

14. Training aids were used effectively

15. Details of training aids could be clearly seen

16. Instructor's overheads/slides helped me locate relevant entries in the publications

17. Instructor's visual aids for strip forms worked effectively

18. Instructor's drawings and/or writing during class were clear and understandable

19. The film/videotape was informative

20. The film/videotape was clearly seen and heard

21. Table space was adequate to accommodate publications, charts, and to perform plotting

22. Charts and publications were used without problems

\section{- Interaction/Participation}

23. Interaction between instructors and students was sufficient to support learning objectives

24. Class participation was sufficient to support learning objectives

25. Students aided one another in performing the computations

26. Instructor gave equal attention to all students

\section{Traditional $\square$ vTt Local D}

Figure 6. Student questionnaire ratings for training aids and interaction (items 14-26).
Disagree Agree

$\begin{array}{lllll}1 & 2 & 3 & 4 & 5\end{array}$
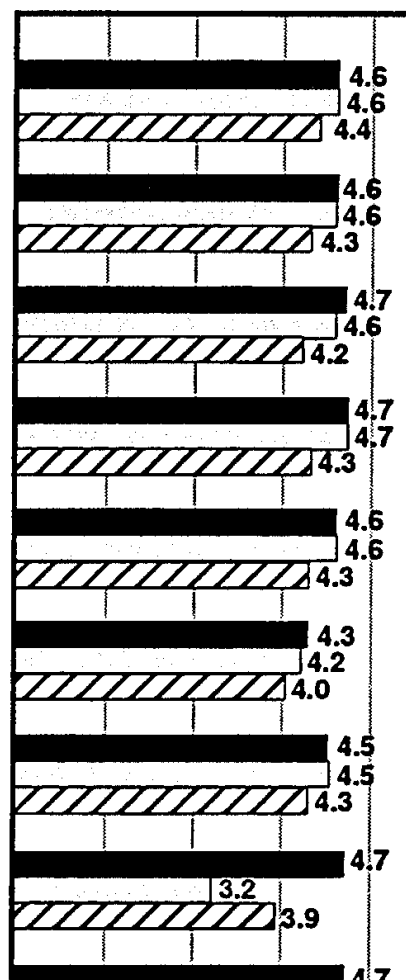

4.4

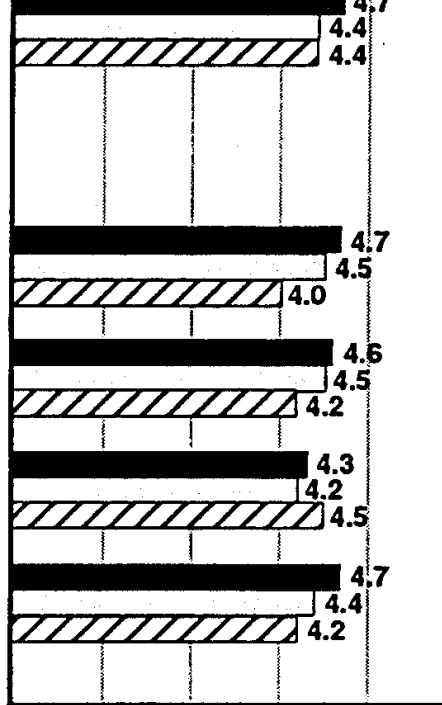




\section{Question}

\section{- Overall}

27. Instructor(s) compare favorably with the best Navy instructors I have had in the past

28. This course compares favorably with the best Navy courses I have taken in the past

29. I found the course material to be difficult

30. The pace of the course was:

[1] Too slow... [3] About right... [5] Too fast

- Video-Teletraining

34. Instructors coordinated activities among classes effectively

35. Local and remote sites participated equally in the class

36. The instructor called on students at all of the sites about equally

37. The VTT facilitators assisting the instructor were helpful to students in the class

\section{Traditional $\square$ vTt Local QZ vTr Remote}

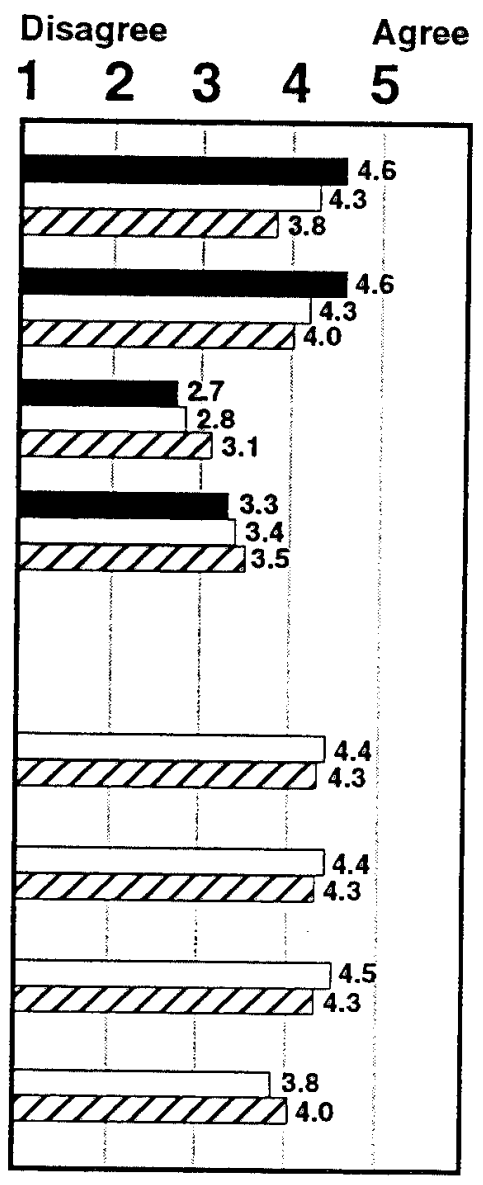

Figure 7. Student questionnaire ratings for course overall and videoteletraining (items 27-30 and 34-37.

Ratings for the instructors and audio-visual adequacy were assessed in items 1-6. The pattern of results over these questions was very similar and group differences on all items were statistically significant. The traditional and VTT local student ratings were about a half of a rating unit above those of the VTT remote students. The pattern of Tukey HSD comparisons showed that the VTT remote students gave significantly lower ratings than either traditional or VTT local students. Traditional and VTT local students did not differ significantly from one another on these items.

Items 7-13 addressed learning and classroom activity issues. Significant group differences were obtained on all but one of these items (item 7). The presentation of computational procedures was given a lower rating by remote site students compared to the other two groups, although their rating was still high (item 8). The results for item 9 indicate that remote site students were more likely to hesitate to ask questions to clarify concepts or steps in the computations. The remote site students differed by .90 and .82 of a rating unit from traditional and local students on this question. Similarly, in rating the help received on computational problems when it was needed (item 10), remote site students were about three quarters of rating unit lower relative to traditional and VTT local students. Remote site students also rated the feedback on assigned problems lower than either traditional or VTT local students on item 13. 
Table 1

Statistical Comparisons for Student Questionnaire Rating Items

\begin{tabular}{|c|c|c|c|c|c|}
\hline \multirow[b]{2}{*}{ Question } & \multicolumn{2}{|c|}{$\begin{array}{c}\text { ANOVA } \\
\text { T-L-R or L-R }\end{array}$} & \multicolumn{3}{|c|}{$\begin{array}{l}\text { Mean Differences and } \\
\text { Tukey HSD Comparisons }\end{array}$} \\
\hline & $\mathrm{DF}$ & $\mathrm{F}$ & T-L & $\mathrm{T}-\mathrm{R}$ & L-R \\
\hline \multicolumn{6}{|l|}{ Instructors } \\
\hline 1. Instructors presented lessons clearly & 2,237 & $17.40^{* *}$ & 0.15 & $0.58^{* *}$ & $0.43^{* *}$ \\
\hline 2. Instructors encouraged class participation & 2,238 & $8.47^{* *}$ & 0.17 & $0.48 * *$ & $0.31 * *$ \\
\hline $\begin{array}{l}\text { 3. Instructors answered student questions } \\
\text { adequately }\end{array}$ & 2,238 & $17.47^{* *}$ & 0.16 & $0.68 * *$ & $0.52^{* *}$ \\
\hline 4. Instructors could be seen clearly & 2,237 & $15.91^{* *}$ & 0.07 & $0.45^{* *}$ & $0.38^{* *}$ \\
\hline 5. Instructors could be heard adequately & 2,238 & $18.92^{* *}$ & 0.10 & $0.54^{* *}$ & $0.44^{* *}$ \\
\hline $\begin{array}{l}\text { 6. Instructors helped students who needed } \\
\text { assistance }\end{array}$ & 2,237 & $16.23^{* *}$ & 0.20 & $0.69 * *$ & $0.49 * *$ \\
\hline \multicolumn{6}{|l|}{ Learning and Classroom Activities } \\
\hline $\begin{array}{l}\text { 7. Concepts or theory underlying the } \\
\text { computations were adequately presented }\end{array}$ & 2,238 & 2.02 & 0.10 & 0.27 & 0.18 \\
\hline $\begin{array}{l}\text { 8. Computational procedures were adequately } \\
\text { presented }\end{array}$ & 2,238 & $9.52^{* *}$ & 0.12 & $0.43^{* *}$ & $0.32^{* *}$ \\
\hline $\begin{array}{l}\text { 9. I hesitated to ask questions in order to clarify } \\
\text { concepts or steps in the computations }\end{array}$ & 2,237 & $13.02^{* *}$ & -0.08 & $-0.90 * *$ & $-0.82^{* *}$ \\
\hline $\begin{array}{l}\text { 10. I received help on computational problems } \\
\text { when I needed it }\end{array}$ & 2,236 & $19.81^{* *}$ & 0.05 & $0.74^{* *}$ & $0.69 * *$ \\
\hline $\begin{array}{l}\text { 11. I had access to the classroom when class was } \\
\text { not in session }\end{array}$ & 2,234 & $19.82^{* *}$ & $1.15^{* *}$ & 0.41 & $-0.74 * *$ \\
\hline 12. I had access to instructors outside of class & 2,233 & $39.31^{* *}$ & $0.70^{* *}$ & $1.69 * *$ & $0.99 * *$ \\
\hline $\begin{array}{l}\text { 13. Assigned problems were graded to provide } \\
\text { feedback }\end{array}$ & 2,235 & $22.00 * *$ & 0.21 & $0.74 * *$ & $0.54^{* *}$ \\
\hline \multicolumn{6}{|l|}{ Training Aids/Materials } \\
\hline 14. Training aids were used effectively & 2,238 & $4.21 *$ & -0.02 & $0.22 *$ & $0.24^{*}$ \\
\hline 15. Details of training aids could be clearly seen & 2,238 & $5.12^{* *}$ & 0.02 & $0.33^{*}$ & $0.31^{*}$ \\
\hline $\begin{array}{l}\text { 16. Instructor's overheads/slides helped me } \\
\text { locate relevant entries in the publications }\end{array}$ & 2,237 & $8.34 * *$ & 0.13 & $0.48^{* *}$ & $0.35^{* *}$ \\
\hline $\begin{array}{l}\text { 17. Instructor's visual aids for strip forms } \\
\text { worked effectively }\end{array}$ & 2,237 & $10.43^{* *}$ & 0.04 & $0.38 * *$ & $0.34^{* *}$ \\
\hline $\begin{array}{l}\text { 18. Instructor's drawings and/or writing during } \\
\text { class were clear and understandable }\end{array}$ & 2,238 & $4.85^{* *}$ & 0.01 & $0.29 *$ & $0.27^{*}$ \\
\hline 19. The film/videotape was informative & 2,237 & $3.03 *$ & 0.17 & $0.38^{*}$ & 0.21 \\
\hline $\begin{array}{l}\text { 20. The film/videotape was clearly seen and } \\
\text { heard }\end{array}$ & 2,237 & 2.86 & -0.02 & 0.20 & 0.22 \\
\hline $\begin{array}{l}\text { 21. Table space was adequate to accommodate } \\
\text { publications, charts, and to perform plotting }\end{array}$ & 2,235 & $31.30^{* *}$ & $1.46^{* *}$ & $0.79 * *$ & $-0.67 * *$ \\
\hline $\begin{array}{l}\text { 22. Charts and publications were used without } \\
\text { problems }\end{array}$ & 2,237 & $4.62^{*}$ & $0.32 *$ & $0.33^{*}$ & 0.01 \\
\hline
\end{tabular}

Mean differences are: $\mathrm{T}-\mathrm{L}=$ Traditional-Local; $\mathrm{T}-\mathrm{R}=$ Traditional-Remote; $\mathrm{L}-\mathrm{R}=$ Local-Remote.

${ }^{*} p<.05,{ }^{* *} p<.01$.

Scale for all items except \#30 is: (1) Strongly Disagree, (2) Disagree, (3) Neither Agree/Disagree, (4) Agree,

(5) Strongly Agree. 
Table 1 (Continued)

\begin{tabular}{|c|c|c|c|c|c|}
\hline \multirow[b]{2}{*}{ Question } & \multicolumn{2}{|c|}{$\begin{array}{c}\text { ANOVA } \\
\text { T-L-R or L-R }\end{array}$} & \multicolumn{3}{|c|}{$\begin{array}{l}\text { Mean Differences and } \\
\text { Tukey HSD Comparisons }\end{array}$} \\
\hline & $\mathrm{DF}$ & $\mathrm{F}$ & $\mathrm{T}-\mathrm{L}$ & $\mathrm{T}-\mathrm{R}$ & L-R \\
\hline \multicolumn{6}{|l|}{ Interaction/Participation } \\
\hline $\begin{array}{l}\text { 23. Interaction between instructors and students } \\
\text { was sufficient to support learning objectives }\end{array}$ & 2,236 & $19.03^{* *}$ & $0.27^{*}$ & $0.70^{* * *}$ & $0.42^{* *}$ \\
\hline $\begin{array}{l}\text { 24. Class participation was sufficient to support } \\
\text { learning objectives }\end{array}$ & 2,236 & $7.49 * *$ & 0.12 & $0.41 * *$ & $0.30 * *$ \\
\hline $\begin{array}{l}\text { 25. Students aided one another in performing the } \\
\text { computations }\end{array}$ & 2,236 & 1.92 & 0.07 & -0.18 & -0.25 \\
\hline $\begin{array}{l}\text { 26. Instructor gave equal attention to all students } \\
\text { Overall }\end{array}$ & 2,236 & $8.05^{* *}$ & 0.22 & $0.52 * *$ & $0.30^{*}$ \\
\hline 27. Instructor(s) compare favorably with the best & & & & & \\
\hline $\begin{array}{l}\text { Navy instructors I have had in the past } \\
\text { 28. This course compares favorably with the }\end{array}$ & 2,237 & $15.56^{* *}$ & 0.31 & $0.83^{* *}$ & $0.52 * *$ \\
\hline best Navy courses I have taken in the past & 2,237 & $5.24 * *$ & 0.29 & $0.51^{* *}$ & 0.22 \\
\hline 29. I found the course material to be difficult & 2,238 & 2.28 & -0.03 & -0.38 & -0.35 \\
\hline $\begin{array}{l}\text { 30. The pace of the course was: (1) too slow, } \\
\text { (2) somewhat slow, (3) about right, } \\
\text { (4) somewhat fast, or (5) too fast } \\
\text { Video-Teletraining }\end{array}$ & 2,237 & 0.96 & -0.11 & -0.18 & -0.07 \\
\hline \multicolumn{3}{|l|}{ Video-Teletraining } & & & \\
\hline $\begin{array}{l}\text { classes effectively } \\
\text { 35. Local and remote sites participated equally }\end{array}$ & 1,185 & $4.06^{*}$ & -- & --- & $0.17^{*}$ \\
\hline $\begin{array}{l}\text { in the class } \\
\text { 36. The instructor called on students at all of the }\end{array}$ & 1,185 & 1.76 & $\cdots$ & -- & 0.13 \\
\hline $\begin{array}{l}\text { sites about equally } \\
\text { 37. The VTT facilitators assisting the instructor }\end{array}$ & 1,183 & $5.51 *$ & $-\cdots$ & --- & $0.21^{*}$ \\
\hline were helpful to students in the class & 1,176 & 2.46 & -- & -- & -0.22 \\
\hline
\end{tabular}
${ }^{*} p<.05,{ }^{* *} p<.01$.

Scale for all items except \#30 is: (1) Strongly Disagree, (2) Disagree, (3) Neither Agree/Disagree, (4) Agree, (5) Strongly Agree. 
Items 11 and 12 appear to reflect a mix of implementation details particular to the VTT classes. For item 11, access to the classroom when the class was not in session was rated lower by VTT local students than either traditional or VTT remote students. This is probably related to the hours at which the VTT local classroom was secured, the instructors returning to their traditional work spaces in another building near the end of the day, and the fact that the instructors' office was adjacent to the classroom for traditional classes. On item 12 , these circumstances may also account for VTT local students having given lower ratings than traditional students on their access to the instructor outside of class. However, access to instructors outside of class is most severely reduced for VTT remote students relative to either VTT local (.99 lower) or traditional students (1.69 lower). The 2.6 average rating of VTT remote students is the lowest rating obtained relative to the other groups over all the items in the questionnaire.

Items 14-22 addressed the training aids and materials used in the course. With the exception of one item (21), most of these items revealed small differences among the treatment groups that did not exceed one half of a rating unit.

For items 14 through 20, the traditional and VTT local students responded virtually the same and the VTT remote students generally gave ratings that were about one third to one fifth of a rating point lower (a significant overall effect was found on each of the items but item 20). VTT remote students gave slightly lower ratings on these items concerned with the effectiveness or visibility of the training aids shown over the system (i.e., use, visibility of details, locating entries in publications, strip form visual aids, instructor drawings and writings, and the videotaped instructional film shown).

All three treatment groups differed significantly from one another on item 21 where the adequacy of table space for publications, charts, and plotting was rated. The traditional classroom for this course has large plotting tables, whereas many VTT classrooms are equipped with 24 " $\mathrm{x}$ $60 "$ tables for a pair of students which are suitable for typical lecture-based courses. Accordingly, the ratings by traditional students are high, but VTT local students give the lowest ratings, with VTT remote students giving ratings intermediate between these two other groups. This pattern of response reflects the fact that during the period of this study the remote sites contained larger tables and fewer students, whereas the VTT local site had many more students sharing physically smaller tables so that the available space per student was less. In rating how well charts and publications could be used in item 22 , both local and remote students responded similarly and gave ratings about a third of a rating unit below the traditional students.

Items 23-26 addressed interaction and participation in the course. A similar significant pattern of response was found on items 23,24 , and 26 . Traditional students rated interaction the highest, followed closely by VTT local students, and VTT remote students gave the lowest ratings. These ratings indicate that instructor-student interaction, class participation, and receiving equal attention from the instructor were perceived to be less by VTT remote students (the group differences ranged from a third to three quarters of a rating point). On item 25 , the slight tendency of remote site students to agree that students aided one another in performing computations was not found significant. However, as will be seen later in discussing item 38 , remote site students were more likely to cite other students as a source of assistance outside of class.

Overall ratings of the instruction were assessed in items 27-30. Significant group differences were found in rating the instructors (item 27) and the course (item 28) relative to prior instructors or courses. VTT remote students gave the lowest ratings, followed by VTT local students, but these 
were still in the "agree" region of the rating scale. VTT remote students gave significantly lower ratings for instructors than traditional and VTT local students, and gave significantly lower ratings of the course than traditional students.

Items 29 and 30 were included in the questionnaire to assess an expectation that remote site students might find the course material more difficult or be more sensitive to the pace of the course. Although the pattern of responses are slightly in this direction, there were no significant group differences to bear out the expectation. Students generally judged both the difficulty and the pace of the course to be just about right, with ratings on these items falling close to the midpoint of the scale.

Rating items 34-37 were completed only by VTT local and remote students because these items pertained only to VTT issues. Group differences on these items were negligible, with the largest differences being only about a fifth of a rating point lower for remote students than local students. Significant differences were shown on items 34 and 36, where remote students gave slightly lower ratings for instructors coordinating activities among classes and calling on all students equally.

\section{Multiple Choice Items}

Items 38-41 were given in a multiple choice format to assess student opportunities to interact with the instructor, assistance received, and preferences for an instructional method. Percentages of response to each choice were calculated for local and remote classrooms, and Chi Square tests were used to compare response distributions by classroom.

Opportunities to interact with instructor. Figure 8 shows student responses to question 40 , which asked "How did the VTT method of instruction affect your opportunities to interact with the instructor?" Nearly nine tenths of the VTT local students responded that their opportunities were unaffected. The majority of VTT remote students were divided in their opinion between there being "no effect" (45.9\%) or "fewer" opportunities (42.6\%). Comparing the two groups, fewer opportunities to interact with the instructor were reported by remote students $(44.6 \%)$ than by local students (7.4\%). A Chi Square test showed that the distribution of responses were significantly different $\left(\chi^{2}(2)=40.78, p<.001\right)$.

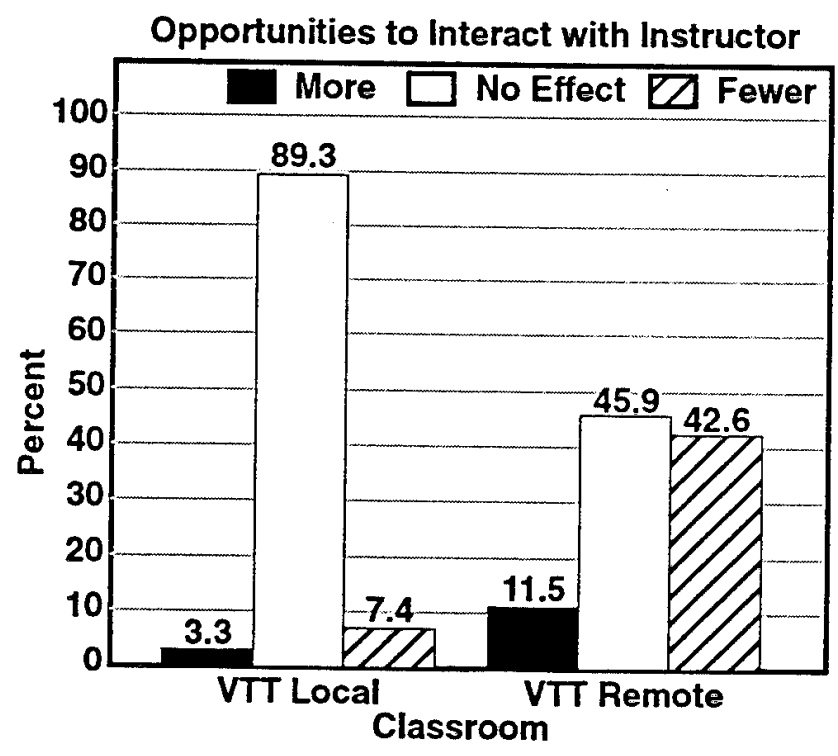

Figure 8. Students responses on how VTT affected opportunities to interact with the instructor (item 40). 
Assistance. Question 38 asked "Who most frequently provided assistance to you outside of regular class hours" and offered choices in terms of "Instructor," "Facilitator," "Other students," and "Other (please explain)." Results to this question are shown in Figure 9. A Chi Square test showed that the distribution of responses among the treatment groups was significantly different $\left(\chi^{2}(6)=76.05, p<.001\right)$.

\section{Source of Student Assistance Outside of Class}

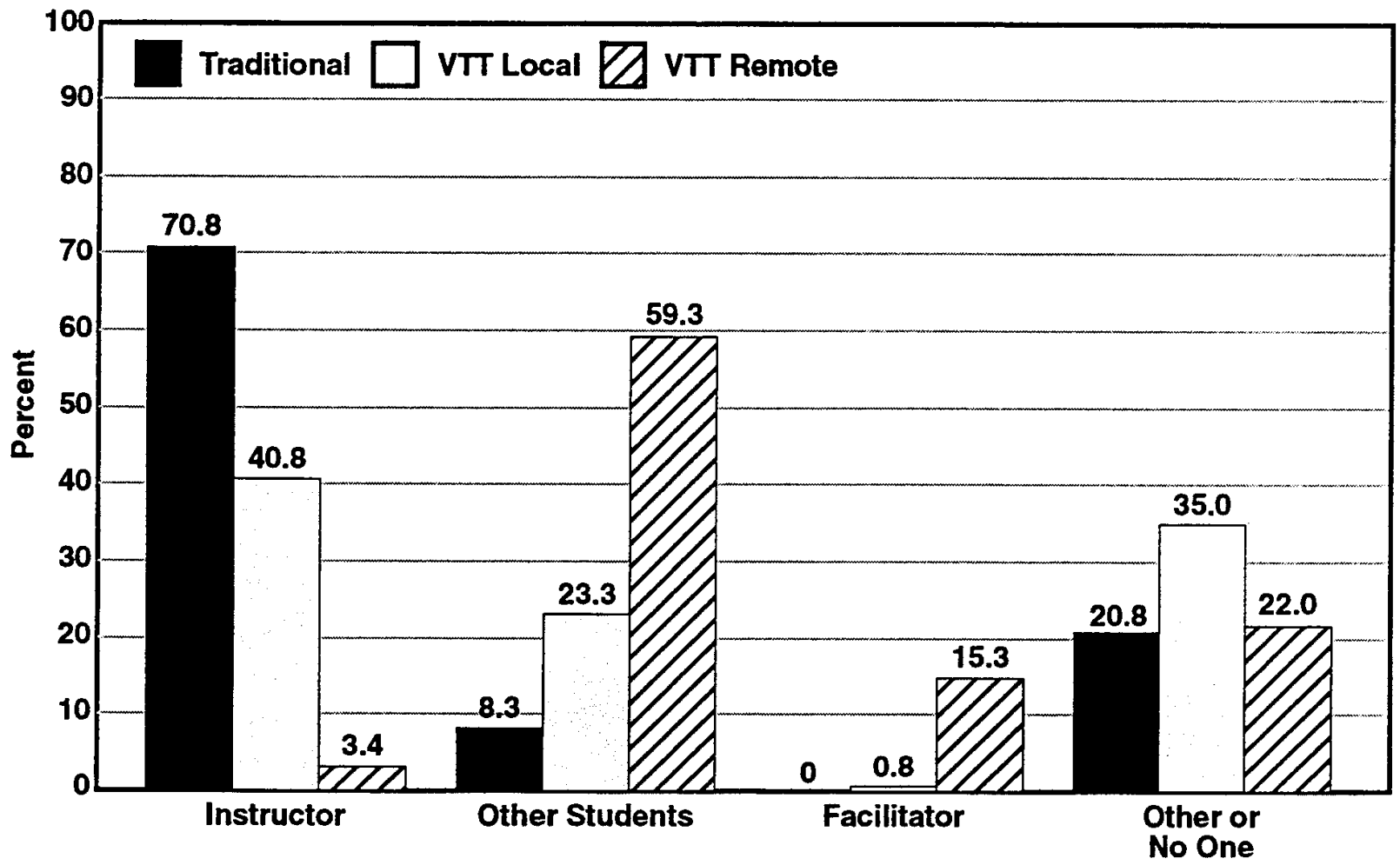

Figure 9. Student responses on who most frequently provided assistance outside of regular class hours (item 38).

The main result of interest in the responses was that VTT remote students cited other students as the main source of assistance outside of class (59.3\%) much more often than did the other groups. The instructor was least often the source of assistance for VTT remote students, whereas the instructor was most often cited as a source by traditional and VTT local students. Remote students clearly cited other students as a source of assistance in this question, but as discussed for item 25 they were only slightly more likely to agree that students aided one another in performing computations. However, item 38 included the phrasing "outside of regular class hours" so that this question may have more explicitly referred to nonlecture laboratory periods at the end of the day when the instructor was not directing activities.

Local students were a little less likely than traditional students to cite the instructor as a source of assistance and a little more likely to cite other students. This result is probably related to the explanation offered for the responses to items 11 and 12. It was observed that the instructor office was adjacent to the classroom for traditional classes, whereas during VTT classes the instructors returned to their traditional work spaces near the end of the day. 
The "Other" category was chosen by one fifth to one third of the students over the three groups. Of those choosing this alternative, about half (52\%) indicated no help was needed, $38 \%$ left the blank empty, and $9 \%$ cited either a combination of response categories or that they received help from someone at their command.

Preference for Instructional Method. Figure 10 reports VTT student preferences for a method of instruction and their willingness to participate in another VTT course (questions 39 and 41).

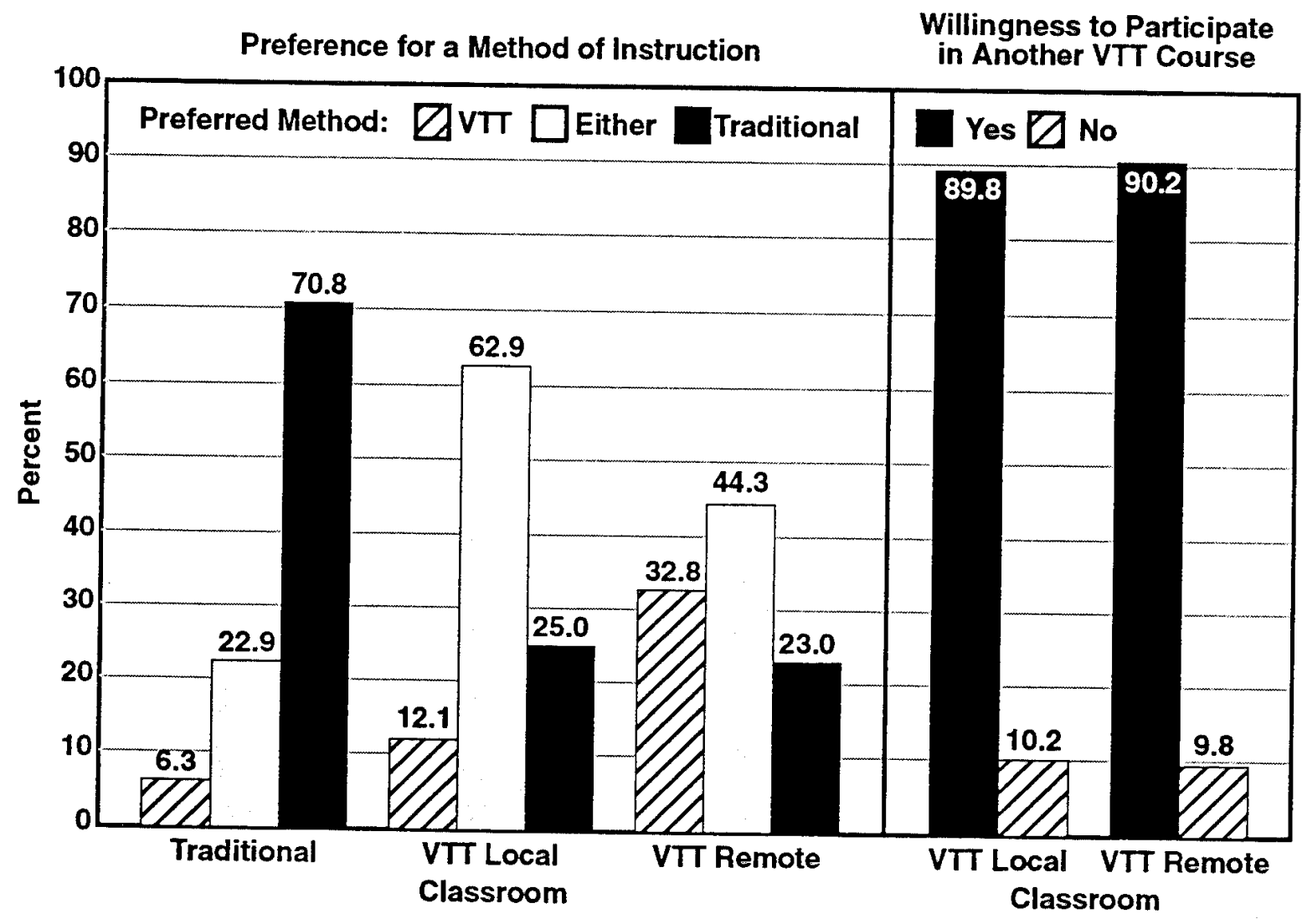

Figure 10. Student preferences for a method of instruction and willingness to participate in another VTT class.

The left hand panel of Figure 10 shows the results for question 39, which asked "Which method of instruction would you prefer for this course?" The responses offered were: Video Tele-Training (VTT), Traditional method (non-VTT), and Either method. Traditional students were given a short description of VTT along with this question. A Chi Square test showed that the distribution of responses to these categories differed significantly among the treatment groups $\left(\chi^{2}(4)=50.46, p<\right.$ $.001)$.

Traditional students were very strongly in favor of the traditional form of instruction $(70.8 \%)$, followed by either method $(22.9 \%)$ and then the VTT method of instruction $(6.3 \%)$. By contrast, the preference for the majority of VTT local students was for "either" method $(62.9 \%)$, followed by the traditional $(25 \%)$ and then the VTT $(12.1 \%)$ methods of instruction. Compared to the these 
two student groups, the VTT remote students were more divided in their preferences. Among VTT remote students, about a tenth more chose "either" method (44.3\%) than chose the VTT method (32.8\%). The remaining quarter of the remote students chose the traditional method (23\%) about as often as did the local students. VTT remote students showed the highest percentage of choice for the VTT method among the three treatment groups (followed by VTT local and then traditional).

The finding that VTT remote students were more favorable toward VTT is notable because these students were at a distance from the instructor and had experienced the full impact of the instructional method. Student acceptance of VTT increases with greater direct experience with the impact of the VTT method when the group responses are ordered from traditional to VTT local to VTT remote. The results support previous observations with instructional television that students may initially have negative perceptions, but these lessen with experience with the medium and become neutral or even positive (cf. Wetzel, et al., 1993, 1994).

The right hand panel of Figure 10 shows the results for question 41 . Students were asked to respond "Yes" or "No" to the question "If you had a choice, would you take another VTT course?" An overwhelming nine tenths of the students at either local or remote sites indicated that they would take another VTT course. A Chi Square test showed no significant difference in the distribution of Yes and No responses among the two treatment groups $\left(\chi^{2}(1)=0.005, p>.05\right)$.

Students were asked to "Please explain" their yes or no response in the second part of question 41. About half of the students did not provide a comment ( $50 \%$ local; $42.6 \%$ remote). About a third of the students offered positive comments, such as savings in travel costs or the ability to teach more students (33.6\% local; $36.1 \%$ remote). A tenth of the comments were negative, such as students being distant from the instructor and their ability to get assistance, or technical problems with VTT (11.7\% local; $9.8 \%$ remote). The remaining students wrote a combination of both positive and negative comments ( $4.7 \%$ local; $11.5 \%$ remote). Thus, the most frequent comment by those who responded was positive and the distribution of responses among the two treatment groups was very similar and did not differ significantly $\left(\chi^{2}(3)=3.44, p>.05\right)$.

\section{Open-Ended Questions}

Questions 42, 43, and 44 asked students what they liked most about the course, what they liked least, and to provide any suggestions to improve the course, respectively. The written responses to each open-ended question were clustered into several categories and percentages within each treatment group were calculated. The results will be discussed briefly here because the responses to these questions did not reveal substantial differences among the treatment groups (summary tables are given in Appendix E).

Comparing the three questions over all treatment groups, students were more likely to respond about what they liked most (82\%), than what they liked least $(64 \%)$, or to suggest improvements $(51 \%)$. Chi Square tests showed that the likelihood of responding with a comment did not differ significantly among the three treatment groups on each of the three questions $\left(\chi^{2}(2)=1.8,3.1,3.2\right.$, $p>.05$, for items 42,43 , and 44 respectively). 
Student comments on what they liked most about the course (item 42) most frequently cited the subject matter as a valuable skill relevant to their jobs (28\% over all groups). The second most frequent comment involved three related categories pertaining to the value of the exercises, practice, and plotting; performing calculations; or the value of these instructional strategies for practical application (20\% over all groups). The next most frequent comment categories involved positive comments about the instructor, the appropriate pace of the course, and positive aspects of using the VTT system. Together, these six categories comprised about $70 \%$ of the comments given on what was liked most about the course. Relative to the other groups, positive comments by remote students were more frequent with regard to VTT and a little less frequent with regard to instructional strategies, exercises, homework, and instructors.

Student comments on what was liked least about the course (item 43) most frequently cited the amount or repetitive nature of the calculations performed for homework (18.5\% over all groups). The second most frequent category cited the pace or length of the course $(12.5 \%$ overall). The remaining responses were distributed among several categories, with a slight tendency for remote students to comment on the instructor or for local students to comment on the facilities. Student comments suggesting improvements for the course (item 44) fell in diverse categories and tended to parallel those on what was liked least about the course. About half of the students provided comments and the most frequent cluster referred to details about the instructional materials, strategies, and exercises (such as homework, forms, and more hands-on work with plotting or the sextant). The next most frequent categories concerned facilities issues such as table space for plotting, the pace of the course, and knowledge of celestial navigation by facilitators.

\section{Summary of Related Questionnaire Topics}

Student responses on the rating items were consistently higher for VTT local and traditional students than for VTT remote students. About two thirds of the items involved a statistically significant less positive rating for remote students compared to local or traditional students (the latter two groups differed significantly in only about a tenth of the items). However, the magnitude of the differences between the treatment groups was generally not large. Additionally, the ratings for all groups were generally high and in a positive direction (about one unit away from the most positive rating on a five point scale). This observed pattern and magnitude of differences is typical of that seen in previous VTT research (Simpson, et al., 1990, 1991a, 1991b, 1992, 1993, 1995; Wetzel, et al., 1995).

A number of the questionnaire items pertained to similar topics even though they were not grouped together in the questionnaire as administered to students. The following paragraphs summarize the general pattern of findings for these topic areas. The magnitude of the difference between the groups differed somewhat over these different topic areas.

For those questions relating to participation issues, ratings by remote students were about one quarter of one rating unit lower than local students and one half a unit lower than traditional students (items $2,23,24,26,34,35,36$ ). Responses were very similar to questions relating to audio-visual factors that had to do with hearing and seeing the instruction (items $4,5,15,16,17$, 18,20 ). Remote site students gave ratings only about one third of a unit lower than local or traditional students. The responses suggest that the various small print publications and strip forms were successfully adapted for delivery by VTT and were not a problem. For questions on instructor 
presentations of instructional content, remote students gave ratings about a third of one unit lower than local students and not quite a half a unit lower than traditional students (items $1,7,8,14,27$ ).

For those questions related to getting help, assistance, feedback, or attention, remote students gave ratings about a half a unit lower than local students and about two thirds a unit lower than traditional students (items $3,6,10,13,26$ ). However, ratings of the difficulty or faster pace of the course were neutral and only a third to a tenth of a unit greater for remote students than the local and traditional students (items 29,30 ). Remote students were noticeably more likely than local students to indicate that they had less access to the instructor (item 12) by a full rating unit and were about 30\% more likely to say they had fewer opportunities to interact with the instructor (item 40). Remote students were also about eight tenths of a unit more likely to indicate a hesitancy to ask questions (item 9).

Facilities related questions reflected conditions during the study period, such as access to the room, that table space for materials was more confined at some facilities, but that the use of charts was not particularly a problem (items $11,21,22$ ). Providing larger rooms and tables to better accommodate this and other courses with hands-on laboratories should be included in future VTT site planning.

Taken together, the largest difference between groups reflected a reduced access to the instructor and assistance related issues for students at a distance, as well as some site specific facilities issues. However, remote students were willing to take another VTT course and their preferences for a method of instruction for this course were not less favorable than local students.

\section{Instructor-Student Interaction and Class Participation}

The tally of interactions in the course was recorded to assess the relative level of instructorstudent interaction among local and remote sites and to assess whether the level of participation by remote student was adequate.

Interaction tallies were recorded during the first three days of class during six class convenings (one local and one remote classroom were always present and a second remote site was present during three of the convenings). There were twice as many local site students $(68.7 \%)$ as remote site students (31.3\%) (101 local and 46 remote students for a total of 147 total students, which attrition reduced to 100 local and 45 remote students by day 3 ).

\section{Categories and Measures}

Interaction Tally Categories. An observer recorded interactions in the seven tally categories that were defined earlier in the method section. Instructor questions (categories 1, 2, and 3) which were answered by a student from either the local or remote site were questions that were either (1) open to any site, (2) named a site, or (3) identified a specific student. Student questions (categories 4 and 5) were asked by either a local or remote site student and were (4) student initiated questions or (5) conversations and exchanges extending beyond a single question. Rater agreement was found to be generally high for these tally categories when two raters observed the same class 
periods. ${ }^{2}$ Three other miscellaneous categories $(6,7,8)$ were also recorded: $(6)$ no answer to an instructor question, (7) no answer to a generic instructor query for "any questions?", and (8) instructor reminders to local site students to use the push-to-talk microphones. Interactions recorded during the six class convenings resulted in a total 3,428 interactions for all eight of these categories and 2,847 for the first five categories.

Interaction Measures. $R$ The interaction counts were converted to two measures that adjusted for variations in the length of time for class periods and the unequal numbers of students between local and remote sites. These two measures were (a) interactions per hour, and (b) interactions per hour per student. Tables in Appendix F illustrate the calculation of these measures and present various summary tables supporting the descriptions of the interaction patterns that are given below.

The interactions per hour measure compensates for recording periods that were not always equal for various reasons (e.g., over different class convenings, days of the week, and class periods in the morning and afternoon). This measure reflects the rate of interaction for an average class in an hour. This measure gives the actual level of interaction in the classes observed and does reflect differences in the number of students between local and remote sites.

The interactions per hour per student measure allows local and remote sites with unequal numbers of students to be compared in terms of the level of interaction relative to how many students were available to contribute interactions. This measure adjusts for both unequal time periods and unequal numbers of students. The measures can be interpreted to reflect the rate of interaction appropriate to an average class relative to the number of students contributing interactions.

\section{Instructor and Student Questions}

The upper (a) and lower (b) panels of Figure 11 show the results for VTT local and remote sites in terms of each of the two interaction measures respectively. Each panel shows the individual instructor and student question categories ( 1 to 5), and the result of combining the three instructor ( 1 to 3 ) and two student ( 4 and 5) categories.

The figure shows that the Celestial Navigation classes were heavily "instructor driven" because most interaction resulted from instructor questions rather than from student questions. Relative to the total of all instructor and student question categories ( 1 to 5 ), $78 \%$ of the interactions were instructor questions (categories 1 to 3 ) and $22 \%$ were student questions or conversation exchanges (categories 4 and 5).

The figure also shows that instructors used a mix of different types of questions that were open to any site, directed at a site, or directed at a specific student. The mixture of instructor questions would be judged beneficial because the instructor can assess knowledge levels in both those students likely to respond when they know an answer and those individuals who are less likely to

\footnotetext{
${ }^{2}$ The Pearson correlation between two raters observing the same sessions during three half day periods was 0.975 for 30 pairs of observations (perfect correspondence would be 1.0). Observer agreement was high within the instructor question and student initiated questions categories (ranging from 0.939 to 0.993 ), but was somewhat lower in judging student conversations and exchanges (0.667). Additional details on this data are given in Table F-2 of Appendix F.
} 
participate. Relative to the total of all instructor and student question categories (1 to 5), 32\% were instructor questions open to any site, $20 \%$ named a site, and $26 \%$ were directed toward a specific student. Student initiated questions were $16 \%$ of this total, and student conversations or exchanges were $6 \%$.

Instructor Questions:

(1) Open to Any Site

(2) Names a Site

(3) Specific Student

Student Questions:

(4) Student Initiated

(5) Conversations

Combined:

(1-3) All Instructor Question

(4-5) All Student Questions

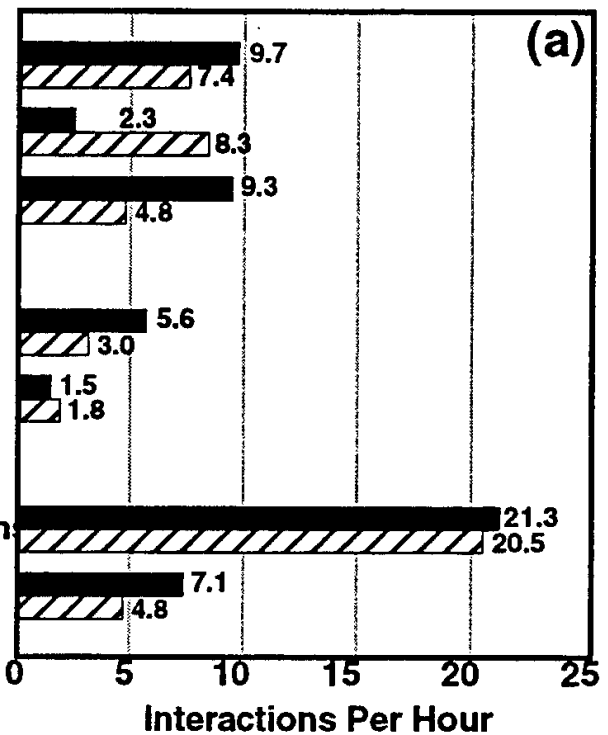

Instructor Questions:

(1) Open to Any Site

(2) Names a Site

(3) Specific Student

Student Questions:

(4) Student Initiated

(5) Conversations

Combined:

(1-3) All Instructor Question

(4-5) All Student Questions

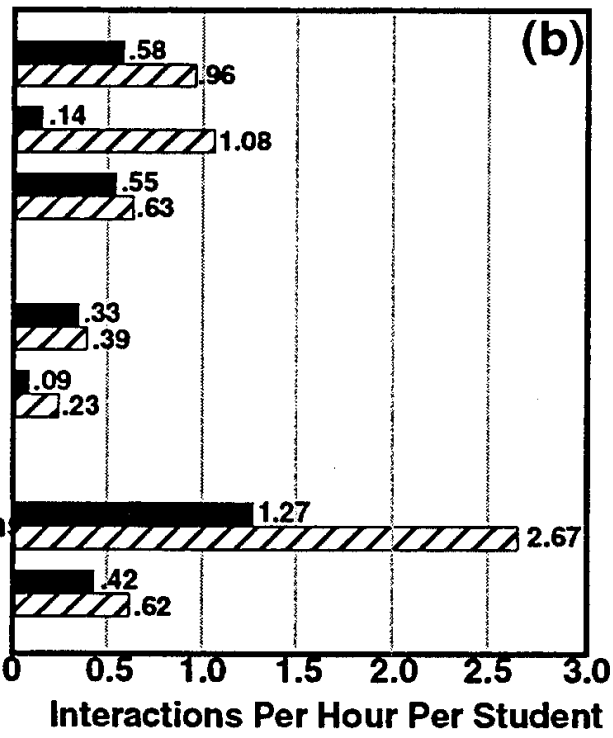

VTT Local D VTT Remote

Figure 11. Interaction tally results for instructor and student questions in terms of (a) interactions per hour, and (b) interactions per hour per student. 
Figure 11a shows the interactions on a per hour basis and reflects the actual overall level of interaction in the course where local students outnumbered remote students. There is a higher level of local than remote site interaction for instructor questions open to any site and those directed toward a specific student. Student initiated questions are also greater at the local site. However, instructor questions that named a local or remote site were much higher for the remote site. The last bars in Figure 11a show that the overall level of instructor questions to local and remote students is nearly the same when all three instructor question categories are combined (1 to 3 ). This is primarily due to the large number of instructor questions that named a site. When the two student question categories are combined (4 and 5), the local students are still more likely to initiate questions.

Figure $11 \mathrm{~b}$ shows the interactions on a per hour per student basis that weights the rate of interaction in terms of the number of local and remote students. By comparing the top and bottom portions of Figure 11 ( $a$ and $b$ ), it is apparent that there is a generally lower level of interaction for remote than local sites in (a), but a higher level of remote than local site interaction in (b). All five instructor and student question categories show at least a slight advantage for remote site students. Thus, relative to their fewer numbers, remote site student interactions are not at a lower level than that of the local site. When all three instructor categories (1 to 3) are combined the remote site students show a level of interaction about twice that of the local students. With all student questions combined (4 and 5) the remote students are only slightly more likely than remote students to ask questions.

The results with this course can be compared to those from a previous study with Navy leadership courses where only student initiated questions and comments were recorded (Wetzel, et al., 1995). For the leadership courses, traditional and local students had about 1.5 interactions per student per hour compared to 1.0 for remote classes. In the present study, the level for local students was 0.42 and was 0.62 for remote students. Thus, there was a lower level of student initiated questions and comments for the Celestial Navigation course than in leadership courses which characteristically involve a more interactive content.

Changes Over Days. The level of interaction generally increased over the three days, but these changes varied somewhat by category (tables in Appendix F summarize these data). Perhaps the most interesting change was that students were about twice as likely to ask questions after the first day of class. There were 7.5, 14.4, and 13.6 questions per hour for days one to three respectively (for student question categories 4 and 5 combined over both local and remote sites). Instructor questions increased mostly on the third day, possibly reflecting topics on that day (38.9, 39.1 , and 52.4 questions per hour for the three days with categories 1 to 3 combined over local and remote sites).

This observed increase in the level of interaction over days was confirmed by an analysis of variance (ANOVA). A two-factor ANOVA was computed using the two treatment groups as a between-subjects factor (local versus remote) and the three days were treated as a within-subjects factor. This analysis is exploratory since there were only six class convenings to be used as subjects in the analysis, which is somewhat small for significance testing. The interactions per hour measure was calculated individually for each of the six classes for each day and treatment group. These individual ratios were computed for an ANOVA of the combined instructor questions (sum of 
categories 1 to 3) and then for an ANOVA of the combined student questions (sum of categories 4 and 5).

The ANOVAs indicated only a significant increase in interactions per hour over the three days of class, as described earlier in this section. For the instructor questions (categories 1 to 3 combined), the effect of days was significant $(F(2,20)=23.74, p<.01)$, but neither the effect of treatment groups $(F(1,10)=1.28, p>.05)$, or the interaction with days were significant $(F(2,20)=$ $0.27, p>.05$ ). For the student questions (categories 4 and 5 combined), the effect of days was significant $(F(2,20)=8.07, p<.01)$, but neither the effect of treatment groups $(F(1,10)=1.48, p>$ $.05)$, or the interaction with days were significant $(F(2,20)=1.88, p>.05)$.

Had these analyses alternatively been conducted using the interactions per hour per student measure, the same pattern of findings would be observed except for a significantly greater level of instructor questions for remote than local students $(\mathrm{F}(1,10)=14.62, \mathrm{p}<.01)$. These analyses support the patterns shown in the grand totals of Figure 11: there were small treatment group differences with the per hour measure, and a larger group difference for instructor questions using the per hour per student measure. That is, the first measure generally shows small differences among groups despite there being half as many remote students, and the second measure shows that the instructor tended to question remote students more often relative to their fewer numbers.

Unanswered Questions. There was a generally low level of instructor questions that were not answered by students. These unanswered questions were either to a specific instructor question (category 6), or to the instructor's generic queries for "any questions?" that were used as a pause before proceeding with the instruction (category 7). Relative to all unanswered and answered instructor questions combined (the sum of categories $1,2,3,6$, and 7 ), $4.9 \%$ were unanswered specific instructor questions and $12.4 \%$ were generic queries for "any questions?"

Students were apparently more likely to provide some response to specific instructor question later in the week (category 6). These unanswered questions declined by about two thirds after the first day of class (4.5, 1.3 and 1.5 events per hour for days one to three respectively).

In a pattern similar to that with the other instructor questions (category 1 to 3 ), the generic query for "Any Questions?" increased later in the week $(5.4,5.9$, and 8.1 events per hour for days one to three).

Reminders to Use Microphones. Whereas VTT remote students must use microphones to talk to the local site, VTT local students in the same room with the instructor can speak directly to the instructor without using the microphones. Although VTT local students are told to use the pushto-talk microphones when asking questions early on the first day of class, they occasionally need to be reminded so that their questions can be heard by remote site students (interaction category 8 ). Figure 12 shows the number of instructor reminders per hour that were given to the VTT local students over the morning and afternoon for the first three days of class. The number of reminders decreases regularly over days from three reminders per hour on the first morning to half that on the third afternoon. The level for mornings and afternoons is similar on the last two days, but on the first day a decrease is shown within the day. The results suggest that VTT local students learn to use their microphones over days because instructor admonishments to do so decline. 


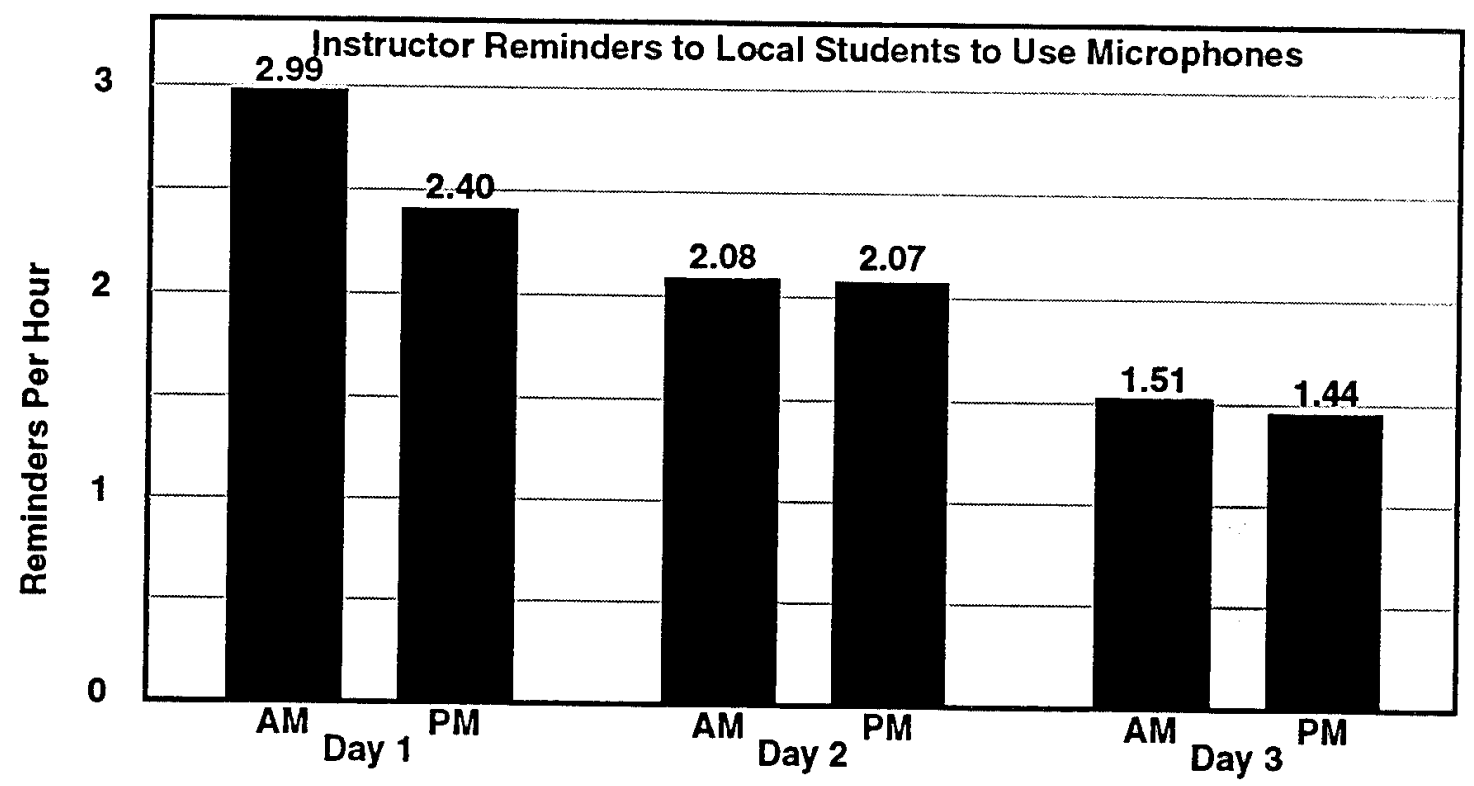

Figure 12. Instructor reminders per hour to local site students to use microphones.

\section{Technology Evaluation Questionnaires}

\section{Picture-in-Picture Evaluation}

The evaluation of picture-in-picture (PIP) technology used in the course involved presenting periods of instruction with PIP enabled or disabled ("Alternating PIP" treatment), or with PIP continuously enabled throughout the course ("Regular PIP Use").

Figure 13 shows the average ratings for eight of the rating items from the PIP Questionnaire given in Appendix B. The first four items shown were rated near the "[4] Agree" region of the five point scale, and the last four items were rated near the "[2] Disagree" region of the scale. The overall pattern of ratings between different questions suggests the following student perceptions. The quality of the presentation was improved by using PIP, it was beneficial to see both the instructor and visuals at the same time, and PIP was used appropriately. The PIP image was clear and there were not usually technical problems. Students were aware that PIP was being used, but they did not think that it was distracting, or that it interfered with seeing the instructor's visuals.

There were generally small differences between the three groups on most of the items shown in Figure 13. However, the first three items show somewhat higher ratings by the remote students than by the local students. Only these first three questions produced a significant group effect by a one-way analysis of variance (ANOVA), which was followed by Tukey HSD tests to test for significant differences between pairs of groups. The quality of the presentation was judged significantly higher by the VTT remote students seeing the alternating PIP than the VTT local students, $F(2,65)=3.79, p<.05$. For the other two questions, the VTT regular PIP use group was significantly higher than the VTT local group with regard to seeing the instructor and visuals at the same time, $F(2,65)=3.81, p<.05$, and with regard to the appropriateness of PIP, $F(2,65)=3.97$, $p<.05$. 


\section{Question:}

The quality of the presentation was improved by using PIP

PIP was beneficial in allowing both the instructor and the visuals to be seen at the same time

PIP was used appropriately

The PIP image was clear

There were usually technical problems in using PIP

I was generally unaware that PIP was being used

Showing the instructor in the PIP was distracting

The PIP interfered with seeing the instructor's visuals

VTT Local - Alternating PIP

VTT Remote - Alternating PIP

Q7 vTT Remote - Regular PIP Use

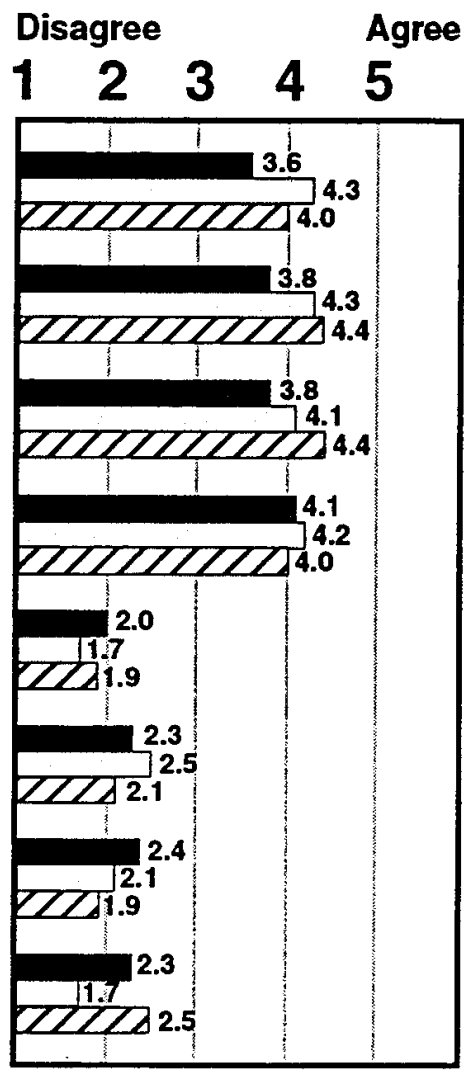

Figure 13. Picture-in-picture questionnaire rating responses.

Figure 14 shows student perceptions of the effectiveness of PIP in providing a rating on each of two questions: "Training was effective with PIP" and "Training was effective without PIP." Ratings for the training effectiveness of PIP were near the "[4] Agree" region of the scale and ratings of training without PIP were near the "[3] neither agree/disagree" middle region of the scale. The remote students show a greater spread between ratings on the two questions, with the PIP presentation being rated slightly higher and the presentation without PIP being rated slightly lower than the ratings given by local students. A two-factor ANOVA was performed with the three treatment groups as a between-subjects factor and the two rating questions as a within-subjects factor. A significant main effect for the two questions indicated that ratings were higher for PIP than without $\mathrm{PIP}, \mathrm{F}(1,65)=38.01, \mathrm{p}<.01$. There was also a significant interaction between the two questions and three treatment groups, $\mathrm{F}(2,65)=3.25, \mathrm{p}<.05$, but the main effect for treatment groups combining the two questions was not significant as a consequence of the interaction pattern shown, $F(2,65)=1.07, \mathrm{p}>.05$. Relative to the local students, the remote students discriminated between the two presentations to a greater extent. Tukey HSD tests indicated that the mean difference between ratings with and without PIP was not significant for the VTT local group (0.51), but this difference was significant $(\mathrm{p}<.05)$ for both the alternating PIP $(1.40)$ and regular PIP use (1.18) VTT remote groups. Thus, the difference or spread between ratings of effectiveness with and without PIP was over twice as large for VTT remote students than it was for VTT local students. 

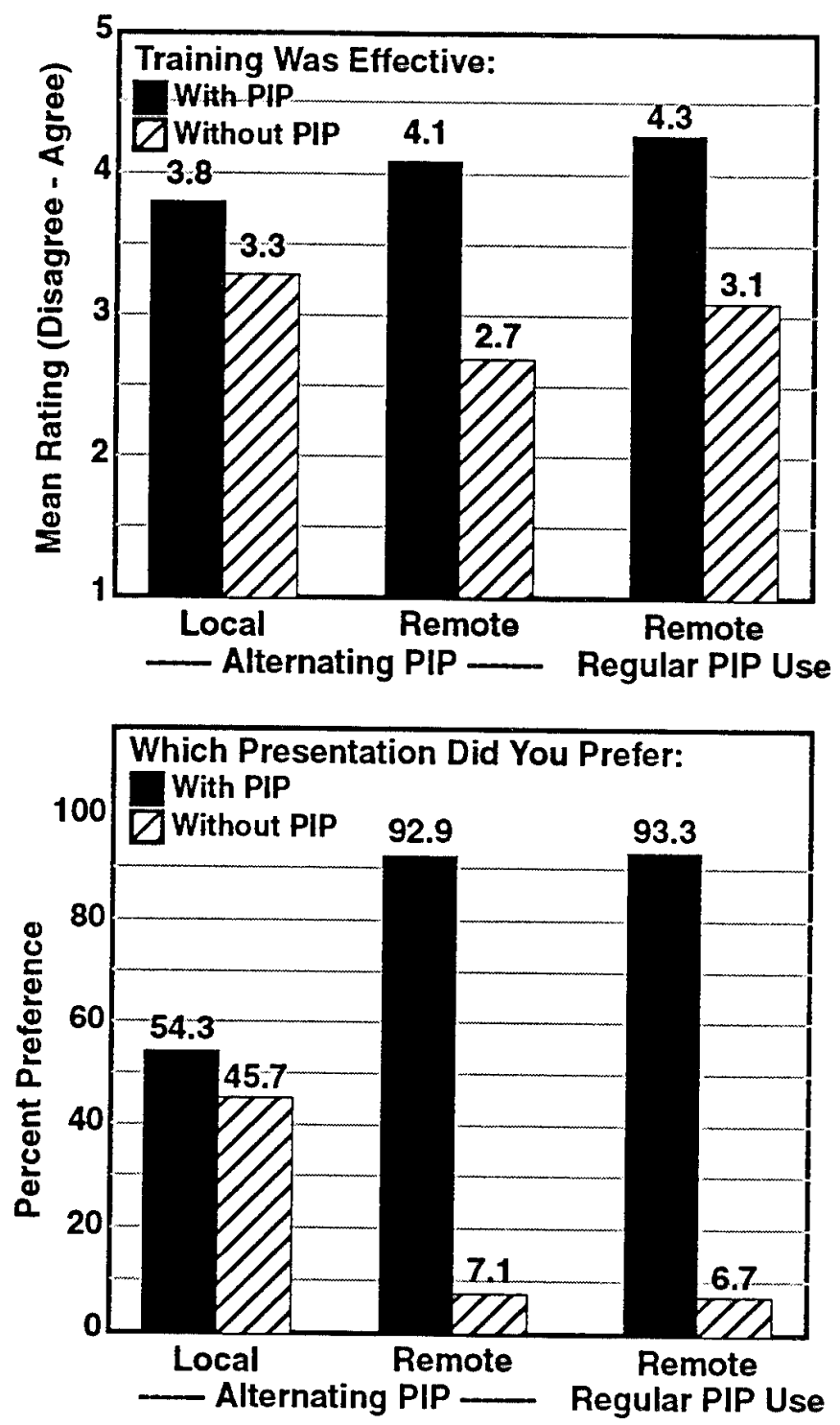

Figure 14. Picture-in-picture questionnaire responses for effectiveness and preference.

Figure 14 shows that the three treatment groups differed substantially in their preferences on the two-choice question asking "Which presentation did you prefer the most?", "When PIP was used" or "When PIP was not used." The VTT local students showed only a slight preference for a presentation with PIP (54.3\%) compared to without PIP (45.7\%). By contrast, both VTT remote groups had a strong preference for the PIP presentation (about 93\%) over not using PIP (about 7\%). A Chi Square test showed that the response distributions differed significantly (Yates corrected $\chi^{2}(2)=9.06, p<.05$ ). (One or two students per group did not answer the question, and if they were included in calculating percent preference then the preference for PIP would be reduced to 51.4, 86.6 and 82.3 percent in the alternating local and remote, and regular PIP remote groups respectively).

Although the VTT remote students in the "Regular PIP Use" group did not see alternating periods with and without PIP, their responses were generally similar to the alternating PIP remote 
site students. Their interpretation of the question on when PIP was not used may have been judged relative to the periods when just the instructor was shown full screen in comparison to the use of PIP when the instructor showed his visuals.

Overall, these results indicate that it is desirable to enable PIP on the outgoing video to remote site students and that it is probably not necessary for local site students. The magnitude of the preference for PIP shown here may reflect the long periods during which visuals are shown on the outgoing video in this course and might not be expected to be as large in other courses using visuals less extensively. Records kept during the first two days of the alternating PIP portion of this study indicate a substantial amount of time during which visuals are shown and the instructor could be off screen. Celestial navigation visuals and strip forms were found to be shown an average of about 10 minutes at a time and to comprise $65 \%$ of the total instruction time (excluding breaks, homework laboratories, and the film).

\section{Electronic Presentation Program Evaluation}

A five item questionnaire was administered to students that asked them to compare a computerized slide presentation lesson using a strip form with the conventional hand-written method used in other lessons (see Appendix C). Four items were rated on the "[1] strongly disagree" to "[5] strongly agree" five point scale, and one item offered a two-alternative choice between the two methods.

The questionnaire was completed by 23 students (15 local and 8 remote) during one class convening. Data for local and remote students were combined because they responded virtually the same, differing by less than two tenths of one rating unit. The four rating items were all rated in the "[4] agree" region of the scale.

Two questionnaire items asked for a rating on whether "Training was effective with the method that used," in one item, "the TV copy stand with paper and hand-writing using a marker pen," and in the other item, "the computerized electronic presentation program." A rating of 4.17 was given to the hand written method and a rating of 3.96 was given to the computerized electronic presentation program. This difference was only 0.21 of a rating unit in favor of the conventional method.

Another pair of questions asked for separate ratings of the readability of text with the two presentation methods. An average rating of 4.32 was given to the item asking if "Text was readable with hand-written method." An average rating of 4.26 was given to the item asking if "Text was readable with computerized presentation." This difference was only 0.06 of a rating unit in favor of the conventional method.

Student preference for the two presentation methods was asked with the question "Which presentation method do you prefer the most?" There were two response alternatives: (a) "TV copy stand with paper and hand-writing with a marker," or (b) "Electronic presentation program." Omitting the 3 students that did not respond, the hand-written method on the TV copy stand was chosen by $55 \%$ of the students and the electronic presentation program was chosen by the other $45 \%$. This slight difference was not significant by a Chi Square test.

The results indicate that there was essentially no difference in effectiveness or readability for either method and that students had little preference for using one method or the other. The 
questionnaire was not administered to additional classes because the obtained differences were so slight with this initial sample of students.

\section{Discussion}

The adaptation of the Celestial Navigation refresher course for delivery by video-teletraining to remote students has been successful. The course has been regularly offered to remote VTT sites from San Diego without any significant problems. This method of delivery is accepted by students and instructors, and the overall direct experience of the instructors has been positive. The initial concerns with the feasibility of delivering the course were overcome as a result of several course conversion techniques and the efforts of the instructors to monitor remote site students. The initial concerns with the feasibility of teaching the course were with the variety of small print visuals used, physical space for plotting, and whether the computational content would be a problem in distant student laboratories. There were only slight trends in the evaluation results in the direction of these concerns. Interaction was at sufficient levels and the VTT sites were able to communicate on performing the computations and on clarifying problems. The principal findings from the evaluation are discussed below in terms of student performance, student evaluations, observed interaction, and course conversion experiences.

\section{Student Performance}

Student performance in all groups was generally at a high level over the three performance measures. Officer students scored at a higher level than did enlisted students and so the groups were examined separately because the enrollment pattern in remote classrooms resulted in many more enlisted students (75\%) than in local and traditional classrooms (44-38\%). Remote students were also slightly more junior than those at local sites.

There was no significant difference between the treatment groups in terms of the percentage of student passing the course (which required $75 \%$ on both the homework and the final examination). The average of the 13 homework assignments during the week was very similar among the three treatment groups and did not differ significantly. There was a small but significant difference between the groups on the final examination where scores were lower at remote sites than at the local site by $4.4 \%$ for officer students and $5.1 \%$ for enlisted students. Statistically controlling for the inequities in student characteristics resulting from the enrollment pattern at remote sites indicated a smaller adjusted difference between local and remote sites of $4.0 \%$ when officerenlisted and military seniority were controlled. Previous studies have found the difference between remote and local sites to range from no difference to five percent (Simpson,.1990, 1991a, 1991b, 1992, 1993, 1995; and studies reviewed in Wetzel, et al., 1994, pp 19-21). Although the rate of passing the course was not affected because performance was still above criterion, the small difference on the final examination stresses the importance of continued monitoring of remote student comprehension during the course. The possibility that some of the lower performance is due to the plotting portion of the examination could be examined in future classes.

\section{Student Attitudes Toward Training}

Student responses on the rating items were consistently higher for VTT local and traditional students than for VTT remote students. However, the magnitude of the differences between the 
treatment groups was generally not large and ratings for all groups were generally high and in a positive direction. The pattern and magnitude of differences observed in this study are typical of that shown in previous VTT research (Simpson, et al., 1990, 1991a, 1991b, 1992, 1993, 1995; Wetzel, et al., 1993, 1994, 1995). Group differences were negligible for topics concerned with class participation, audio-visual factors related to hearing and seeing the instruction, and instructor presentations of material (a third or less of a rating unit group difference on the five point scale). These results indicated that the various small print publications and strip forms were successfully adapted for delivery by VTT.

Remote students gave ratings only about a half a unit lower than local students for most items related to getting help, assistance, feedback or attention. However, there was no significant difference between groups in rating either the difficulty or pace of the course. Remote students were more likely than local students to indicate that they had less access to the instructor by a full rating unit and were about $30 \%$ more likely to say they had fewer opportunities to interact with the instructor. Remote site students were also a little more likely to cite other students as a source of assistance outside of class. However, remote students were willing to take another VTT course and their preferences for a method of instruction for this course were not less favorable than local students. Direct experience with the impact of VTT appeared to increase the extent of student acceptance of VTT--remote students were more accepting of VTT than traditional students without the direct VTT experience.

Facilities related items reflected conditions during the study period, such as access to the room and confined table space for materials at some facilities, but the use of charts was not particularly a problem. Providing larger rooms and tables to better accommodate this and other courses with hands-on laboratories should be included in future VTT site planning.

\section{Interaction and Participation}

The tally of interactions in the course was recorded to assess the relative level of instructorstudent interaction among local and remote sites and to assess whether the level of participation by remote student was adequate. The results with this objective measure indicated that there were adequate levels of remote site student participation and instructor interaction with remote students.

Most of the interactions during class sessions were initiated by instructors in questioning that focused on answers to steps in the computations and assessing other knowledge. Instructors used a mix of questions that were left open to any site, directed at a site, or directed at individual students. The mixture of instructor questions would be judged beneficial because the instructor can assess knowledge levels in both those students who are likely to respond when they know an answer and those individuals who are less likely to participate.

Despite their fewer numbers, remote site students were not disadvantaged in terms of the level of interaction observed. There tended to be fewer interactions per hour associated with the remote sites because there were fewer remote than local site students. When expressed in terms of interactions per student per hour, remote site students received a significantly higher rate of instructor questions associated with their site than did local students.

There was a tendency for both student and instructor interaction to increase over days. In particular, student initiated questions increased after the first day and unanswered instructor 
questions declined after the first day. Local site students overcame their tendency to speak directly to the instructor as the week progressed because there were fewer instructor reminders to use their microphones so remote sites could hear them.

\section{Technology Evaluations}

Picture-in-Picture (PIP) technology was found beneficial for showing both the instructor and visuals such as strip forms during periods when only the visuals and not the instructor would have normally been shown. The use of PIP was generally favored by remote site students. VTT remote students gave higher ratings with regard to the quality of the presentation with PIP and the difference between ratings of effectiveness with and without PIP was also larger. When asked for their preference, remote students overwhelmingly chose the presentation with PIP over the presentation without PIP, while local students were relatively neutral in their preference. This technique could be used for the video sent out to remote students in other courses where an instructor might be off-screen for lengthy periods.

A brief questionnaire also asked students to compare an electronic presentation program lesson with the conventional hand-written method used in other lessons. Students had no preference for using one method or the other and gave the methods similar effectiveness and readability ratings. Thus, the choice of these technologies can be based on practical and efficiency factors.

\section{VTT Course Conversion}

Several aspects of the experience with the Celestial Navigation course are relevant to adapting other courses to VTT. The adaptation of the course required a concerted planning phase to address potential difficulties, revising visual materials, procuring remote site materials, developing new instructor behaviors appropriate to VTT, and developing support mechanisms at remote sites (these topics are discussed in a useful course conversion guide developed for the Navy by Simpson, 1993).

Instructor transparencies must typically be revised to contain fewer lines and words, put in a landscape format with a consistent size, and reproduced on paper to avoid reflections. The approach to the visuals in this course addressed a problem with video displays of the many small print tables in nautical publications. Showing an entire table rendered the small print unreadable and zooming in on relevant text lost the overall context of relevant column and row heading. The critical portions of text were enlarged and arrows indicated where these entries were located on the page so that students could locate entries in their own publications. Lengthy strip forms were also enlarged and segmented into several pages.

Remote site facilitators play an important role as an extension of the instructor for students at a distance. An important principle illustrated in this course was the development of scoring methods that captured the expertise of the instructors and allowed facilitators to act as an extension of the instructor. Facilitators were able to score student plotting charts by using the acetate overlay marked with the correct course, fixes and labeling required of students. A daily schedule of events is another particularly beneficial mechanism that allows facilitators to assist the instructor when there are many materials to be distributed at appropriate times or when laboratory equipment is to be setup. 
Courses that depart from the lecture-based courses typically taught by VTT require additional attention. Courses with special requirements, such as laboratories where students perform their own work, should be monitored in order to ensure that a high quality VTT version of the course continues to be maintained. As remote site facilitators and instructors rotate in their assignments, the training and practical experience bearing on the special concerns of the course need to be conveyed to their replacements.

Classroom facilities also require attention in delivering a wider range of VTT courses that include laboratories. VTT classrooms are used by a variety of courses and are not dedicated to the materials and equipment for just one course. The key to reusing the same room for courses with special requirements is to develop portable methods to allow materials and equipment to be moved in and out of the room. Laboratory courses will also generally require somewhat larger rooms and table space adequate to the student materials. As noted in this study, some sites had small tables that made it more difficult to use the four publications and various small items used in plotting. Other courses with more substantial equipment may require more classroom space, extra storage space between class convenings, and require enhanced electrical power. Although the Celestial Navigation course was a relatively mild form of a laboratory course, the experience with this and other subsequent laboratory courses has suggested the importance of facilities and portability considerations for other future laboratory VTT courses.

Finally, concern for remote site student comprehension and participation is an issue common to a variety of VTT courses. As mentioned previously, instructors in this course consistently used a variety of questioning techniques to make periodic verbal checks on student comprehension. A student roster forwarded from the remote site is beneficial in allowing the instructor to direct questions to individual students, particularly those who are less likely to participate. An adequate level of remote site student initiated participation was also observed in this course. The success of the Celestial Navigation course was related to the development of effective instructor behaviors in attending to remote site students and having learned to use a variety of technologies to delivery effective presentations. The experience with this course also highlights the importance of tight coordination and communication between instructors and remote site facilitators.

\section{Recommendations}

The following recommendations are for the Chief of Naval Education and Training and the CNET Electronic Schoolhouse Network.

1. Delivery of the Celestial Navigation refresher course by videoteletraining has been successful and the use of this method should be expanded to other sites as appropriate to satisfy demand for the course.

2. VTT courses with atypical requirements such as student laboratories should be given special attention to maintain a high quality VTT version of the course. Such attention includes monitoring remote site student comprehension, conveying VTT lessons learned as remote site facilitators and instructors rotate in their assignments, and providing sufficient space for the additional instructional materials found in this and other future laboratory courses. 


\section{References}

Bailey, S. S., Sheppe, M. L., Hodak, G. W., Kruger, R. L., \& Smith, R. F. (1989, December). Video teletraining and video teleconferencing: A review of the literature (Technical Report 89-036). Orlando, FL: Naval Training Systems Center.

Fleiss, J. L. (1981). Statistical methods for rates and proportions. New York, NY: John Wiley and Sons.

Rupinski, T. E. (1991). Analyses of video teletraining utilization, effectiveness, and acceptance (CRM Research Memorandum 91-159). Alexandria, VA: Center for Naval Analyses.

Rupinski, T. E., \& Stoloff, P. H. (1990). An evaluation of Navy video teletraining (VTT) (CRM Research Memorandum 90-36). Alexandria, VA: Center for Naval Analyses.

Simpson, H. (1993). Conversion of live instruction for videoteletraining: Training and classroom design considerations (TN-93-04). San Diego, CA: Navy Personnel Research and Development Center. (AD-A261 051)

Simpson, H., Pugh, H. L., \& Parchman, S. W. (1990). A two-point videoteletraining system: Design, development, and evaluation (NPRDC-TR-90-05). San Diego, CA: Navy Personnel Research and Development Center. (AD-A226 734)

Simpson, H., Pugh, H. L., \& Parchman, S. W. (1991a). An experimental two-way video teletraining system: Design, development and evaluation. Distance Education, 12, 209-231.

Simpson, H., Pugh, H. L., \& Parchman, S. W. (1991b). Empirical comparison of alternative video teletraining technologies (NPRDC-TR-92-3). San Diego, CA: Navy Personnel Research and Development Center. (AD-A242 200)

Simpson, H., Pugh, H. L., \& Parchman, S. W. (1992). The use of videoteletraining to deliver handson training: Concept test and evaluation (NPRDC-TN-92-14). San Diego, CA: Navy Personnel Research and Development Center. (AD-A250 708)

Simpson, H., Pugh, H. L., \& Parchman, S. W. (1993). Empirical comparison of alternative instructional TV technologies. Distance Education, 14, 147-164.

Simpson, H., Wetzel, C. D., \& Pugh, H. L. (1995). Delivery of Division Officer Navy Leadership Training by Videoteletraining: Initial Concept Test and Evaluation. (NPRDC-TR-95-7). San Diego, CA: Navy Personnel Research and Development Center.

Stoloff, P. H. (1991). Cost-effectiveness of U.S. Navy video teletraining system alternatives. (CRM Research Memorandum 91-165). Alexandria, VA: Center for Naval Analyses. 
Wetzel, C. D., Radtke, P. H., \& Stern, H. W. (1993, April). Review of the effectiveness of video media in instruction (NPRDC-TR-93-4). San Diego, CA: Navy Personnel Research and Development Center. (AD-A264 228)

Wetzel, C. D., Radtke, P. H., \& Stern, H. W. (1994). Instructional Effectiveness of Video Media. Hillsdale, NJ: Lawrence Erlbaum Associates, Publishers.

Wetzel, C. D., Simpson, H., \& Seymour, G. E. (1995). The use of videoteletraining to deliver Chief and Leading Petty Officer Navy Leadership Training: Evaluation and Summary (NPRDC-TR95-8). San Diego, CA: Navy Personnel Research and Development Center. 
Appendix A

Celestial Navigation Student Questionnaire 
a. Name

Last First

MI

Rank

b. Today's date

c. Location [ ] San Diego

[ ] Treasure Island

[ ] Bangor

For each of the statements followed by [1] [2] [3] [4] [5], please check the box indicating how well you agree with the statement using this scale:

$\begin{array}{ccccc}{[1]} & {[2]} & {[3]} & {[4]} & {[5]} \\ \text { Strongly } & \text { Disagree } & \text { Neither } & \text { Agree } & \text { Strongly } \\ \text { Disagree } & & \text { Agree/ } & & \text { Agree } \\ & & \text { Disagree } & & \end{array}$

INSTRUCTORS

1. Instructors presented lessons clearly

2. Instructors encouraged class participation

3. Instructors answered student questions adequately

4. Instructors could be seen clearly

5. Instructors could be heard adequately

6. Instructors helped students who needed assistance
Disagree Agree

$S D \quad D \quad N \quad A \quad S A$

[1] [2] [3] [4] [5]

[1] [2] [3] [4] [5]

[1] [2] [3] [4] [5]

[1] [2] [3] [4] [5]

[1] [2] [3] [4] [5]

[1] [2] [3] [4] [5]

\section{LEARNING \& CLASSROOM ACTIVITIES}

7. Concepts or theory underlying the computations were adequately presented

8. Computational procedures were adequately presented

9. I hesitated to ask questions in order to clarify concepts or steps in the computations

10. I received help on computational problems when I needed it

11. I had access to the classroom when class was not in session

12. I had access to instructors outside of class

13. Assigned problems were graded to provide feedback

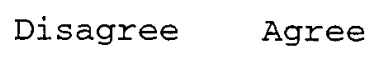

$S D \quad D \quad N \quad A \quad S A$

[1] [2] [3] [4] [5]

[1] [2] [3] [4] [5]

[1] [2] [3] [4] [5]

[1] [2] [3] [4] [5]

[1] [2] [3] [4] [5]

[1] [2] [3] [4] [5]

[1] [2] [3] [4] [5] 
TRAINING AIDS

14. Training aids were used effectively

15. Details of training aids could be clearly seen

16. Instructor's overheads/slides helped me locate relevant entries in the publications

17. Instructor's visual aids for strip forms worked effectively

18. Instructor's drawings and/or writing during class were clear and understandable

19. The film/videotape was informative

20. The film/videotape was clearly seen and heard

21. Table space was adequate to accommodate publications, charts, and to perform plotting

22. Charts and publications were used without problems
Disagree Agree

$S D \quad D \quad N \quad A \quad S A$

[1] [2] [3] [4] [5]

[1] [2] [3] [4] [5]

[1] [2] [3] [4] [5]

[1] [2] [3] [4] [5]

[1] [2] [3] [4] [5]

[1] [2] [3] [4] [5]

[1] [2] [3] [4] [5]

[1] [2] [3] [4] [5]

[1] [2] [3] [4] [5]
INTERACTION/PARTICIPATION

23. Interaction between instructors and students was sufficient to support learning objectives

24. Class participation was sufficient to support learning objectives

25. Students aided one another in performing the computations

26. Instructor gave equal attention to all students

\begin{tabular}{clll} 
Disagree & \multicolumn{2}{c}{ Agree } \\
SD D N & A SA
\end{tabular}

[1] [2] [3] [4] [5]

[1] [2] [3] [4] [5]

[1] [2] [3] [4] [5]

[1] [2] [3] [4] [5]
OVERALL

27. Instructor(s) compare favorably with the best Navy instructors I have had in the past

28. This course compares favorably with the best Navy courses I have taken in the past

29. I found the course material to be difficult

\section{Disagree Agree}

$S D$ D N A SA

[1] [2] [3] [4] [5]

[1] [2] [3] [4] [5]

[1] [2] [3] [4] [5] 
30. The pace of the course was:

$\begin{array}{ccccc}{[\text { ] }} & {[\text { ] }} & {[\text { ] }} & {[\text { ] }} & {[\text { ] }} \\ \text { Too-Slow } & \text { Somewhat-Slow } & \text { About-right } & \text { Somewhat-Fast } & \text { Too-Fast }\end{array}$

BACKGROUND

Disagree Agree

31. Before this course, I was proficient at manually performing the celestial navigation computations

SD $\quad D \quad N \quad A \quad S A$

32. I previously had experience in manually performing

the celestial navigation computations in this course:

[ ] No

[ ] Yes, on-the-job experience

[ ] Yes, course work

[ ] Yes, both on-the-job experience and course work

[ ] Other (please explain):

33. Will your duties or next assignment directly involve application of skills from this course:

[ ] No

[ ] Yes, infrequently for shipboard duties

[ ] Yes, routinely for shipboard duties

[ ] The course was primarily for advancement purposes

[ ] Other (please explain):

VIDEO-TELETRAINING

34. Instructors coordinated activities among classes effectively

35. Local and remote sites participated equally in the class

36. The instructor called on students at ali of the sites about equally

37. The VTT facilitators assisting the instructor were helpful to students in the class

38. Who most frequently provided assistance to you outside of regular class hours:
[ ] Instructor
[ ] Facilitator
[ ] Other students
[ ] Other (please explain):

39. Which method of instruction would you prefer for this course:

[ ] Video Tele-Training (VTT)

[ ] Traditional method (non-VTT)

[ ] Either method

\section{Disagree Agree \\ $S D \quad D \quad N \quad A \quad S A$}

[1] [2] [3] [4] [5]

[1] [2] [3] [4] [5]

[1] [2] [3] [4] [5]

[1] [2] [3] [4] [5] 
40. How did the VTT method of instruction affect your opportunities to interact with the instructor?

[ ] more opportunities

[ ] no effect on opportunities

[ ] fewer opportunities

41. If you had a choice, would you take another VTT course?

[ ] Yes

[ ] No

Please explain:

COMMENTS: Please answer the following questions by writing in your comments on the blank lines.

42. What did you like the most about this course?

43. What did you like the least about this course?

44. Discuss any suggestions you have for improving the course 


\section{Appendix B}

Picture-in-Picture Questionnaire 
Picture-in-Picture (PIP) was used during some of your lectures to show a second image inserted within a window in the larger image on the screen. For example, one image showed the instructor and the other showed training aids such as graphics, slides or writings made by the instructor. Please evaluate this technique in terms of its effectiveness and your preference.

For each of the statements followed by [1] [2] [3] [4] [5], please check the box indicating how well you agree with the statement using this scale:

$\begin{array}{ccccc}{[1]} & {[2]} & {[3]} & {[4]} & {[5]} \\ \text { Strongly } & \text { Disagree } & \text { Neither } & \text { Agree } & \text { Strongly } \\ \text { Disagree } & & \text { Agree/ } & & \text { Agree } \\ & & \text { Disagree } & & \end{array}$

Check Site: [ ] San Diego

Date:

Name of Course:

\section{Disagree Agree}

1. The quality of the presentation was improved by using PIP [1] [2] [3] [4] [5]

2. The PIP interfered with seeing the instructor's visuals

[1] [2] [3] [4] [5]

3. I was generally unaware that PIP was being used

[1] [2] [3] [4] [5]

4. Showing the instructor in the PIP was distracting

[1] [2] [3] [4] [5]

5. PIP was beneficial in allowing both the instructor

[1] [2] [3] [4] [5] and the visuals to be seen at the same time

6. There were usually technical problems in using PIP

7. PIP was used appropriately

[1] [2] [3] [4] [5]

8. The PIP image was clear

9. Training was effective WITH PIP

10. Training was effective WITHOUT PIP

11. Which presentation did you prefer the most ?

[ ] When PIP WAS used

[ ] When PIP WAS NOT used

Please comment on the use of PIP in the course: 
Appendix C

Electronic Presentation Program Questionnaire 
Electronic Presentation Program Questionnaire (Addendum to Celestial Navigation Questionnaire)

Your instructor used two different presentation technologies to show his graphics and strip forms:

(1) A conventional hand-written method using paper on the TV copy stand, e.g., he wrote on a paper strip form with a marker.

(2) A computerized electronic presentation program (VideoShow), e.g., entries in the electronic stripform were revealed one at a time.

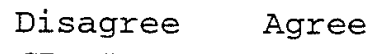

A. Training was effective with the method that used:

the TV copy stand with paper and hand-writing using a marker pen.

[1] [2] [3] [4] [5]

B. Training was effective with the method that used:

the computerized electronic presentation program.

[1] [2] [3] [4] [5]

C. Which presentation method do you prefer the most:

(please pick only one)

[ ] TV copy stand with paper and hand-writing with a marker

[ ] Electronic presentation program (VideoShow)

D. Text was readable with hand-written method

[1] [2] [3] [4] [5]

E. Text was readable with computerized presentation

[1] [2] [3] [4] [5]

Please provide any comments on these two methods: 


\section{Appendix D}

Student Groups and Performance Summary Tables 
Table D-1

Number of Students Per Measure and Average Military Rank

\begin{tabular}{|c|c|c|c|c|}
\hline \multirow[b]{2}{*}{ Group and Measure } & \multicolumn{4}{|c|}{ Treatment Group } \\
\hline & VTT Local & VTT Remote* & Traditional & Prior Traditional \\
\hline \multicolumn{5}{|l|}{ Student Grades: } \\
\hline Number of Officer Students & 76 & 16 & 48 & 48 \\
\hline Mean Military Rank** & 2.7 & 2.4 & 2.7 & 2.5 \\
\hline Median Military Rank & 3.0 & 3.0 & 3.0 & 3.0 \\
\hline Number of Enlisted Students & 59 & 50 & 30 & 43 \\
\hline Mean Military Rank** & 5.5 & 4.8 & 4.1 & 5.6 \\
\hline Median Military Rank & 6.0 & 5.0 & 4.0 & 6.0 \\
\hline Total Number of Students & 135 & 66 & 78 & 91 \\
\hline Number of Classes & 9 & 9 & 5 & 5 \\
\hline \multicolumn{5}{|l|}{ Students Completing Questionnaire: } \\
\hline Number of Students & 128 & 61 & 52 & - \\
\hline Number of Classes & 9 & 9 & 3 & - \\
\hline \multicolumn{5}{|l|}{ Students in Interaction Tally: } \\
\hline Number of Students & 101 & 46 & - & - \\
\hline Number of Classes & 6 & 6 & - & - \\
\hline
\end{tabular}

* VTT remote students were primarily at Treasure Island. Of the total shown, the Bangor remote site contributed 12 students in 5 classes for the grades, 9 students in 3 classes for questionnaires, and 10 students in 3 classes for the interaction tally. **Military rank for Officers ranged from O-1 to O-5; Enlisted ranged from E-2 to E-8.

Note: Treatment group data were collected during the following time periods:

Nine VTT classes between June 1993 and August 1994.

Five traditional classes were May, June, and July 1993, and March and May 1994 (questionnaires were administered in the last three traditional classes).

Five prior traditional were April, March, February, and Jan 1993, and Dec 1992. 
Table D-2

Homework Average Percent Correct, Standard Deviations, and Number of Students

\begin{tabular}{|c|c|c|c|c|}
\hline \multirow[b]{2}{*}{ Group and Measure } & \multicolumn{4}{|c|}{ Treatment Group } \\
\hline & VTT Local & VTT Remote & Traditional & Prior Traditional \\
\hline \multicolumn{5}{|l|}{ Officer: } \\
\hline Mean & 95.86 & 95.55 & 96.50 & 95.54 \\
\hline Standard Deviation & 3.74 & 3.47 & 3.21 & 4.22 \\
\hline Number of Students & 76 & 16 & 48 & 48 \\
\hline \multicolumn{5}{|l|}{ Enlisted: } \\
\hline Mean & 91.09 & 92.38 & 92.44 & 92.98 \\
\hline Standard Deviation & 9.36 & 5.77 & 4.93 & 8.61 \\
\hline Number of Students & 59 & 50 & 30 & 43 \\
\hline
\end{tabular}

Table D-3

Final Examination Average Percent Correct, Standard Deviations, and Number of Students

\begin{tabular}{|c|c|c|c|c|}
\hline \multirow[b]{2}{*}{ Group and Measure } & \multicolumn{4}{|c|}{ Treatment Group } \\
\hline & VTT Local & VTT Remote & Traditional & Prior Traditional \\
\hline \multicolumn{5}{|l|}{ Officer: } \\
\hline Mean & 96.69 & 92.28 & 95.52 & 88.82 \\
\hline Standard Deviation & 3.19 & 5.49 & 5.18 & 6.58 \\
\hline Number of Students & 76 & 16 & 48 & 48 \\
\hline \multicolumn{5}{|l|}{ Enlisted: } \\
\hline Mean & 92.47 & 87.32 & 90.86 & 86.17 \\
\hline Standard Deviation & 9.17 & 10.26 & 11.25 & 11.02 \\
\hline Number of Students & 59 & 49 & 30 & 43 \\
\hline \multicolumn{5}{|l|}{ Combined Officer + Enlisted: } \\
\hline Actual Mean & 94.85 & 88.55 & 93.73 & 87.57 \\
\hline Adjusted Mean $(\mathrm{OE})^{*}$ & 94.58 & 89.70 & 93.23 & - \\
\hline Adjusted Mean (OE \& Rank) & 94.34 & 90.31 & 93.14 & - \\
\hline
\end{tabular}

* Note: Adjusted means are based on analysis of covariance predictions using Officer-Enlisted status (OE) or OE status and Z-score military rank as covariates. Note: Enlisted VTT remote based on 49 students because numeric value of one failing score not recorded for 50 students. 
Table D-4

Percentage and Number of Student Passing or Failing the Course, Homework, and Final Examination.

\begin{tabular}{|c|c|c|c|c|}
\hline \multirow[b]{2}{*}{ Group and Measure } & \multicolumn{4}{|c|}{ Treatment Group } \\
\hline & VTT Local & VTT Remote & Traditional & Prior Traditional \\
\hline \multicolumn{5}{|l|}{ Officer: } \\
\hline Percent Passing & 100.00 & 100.00 & 100.00 & 100.00 \\
\hline Percent Failing & 0.00 & 0.00 & 0.00 & 0.00 \\
\hline Number Passing & 76 & 16 & 48 & 48 \\
\hline Number Failing & 0 & 0 & 0 & 0 \\
\hline Total (Passing + Failing) & 76 & 16 & 48 & 48 \\
\hline Number Failing Homework & 0 & 0 & 0 & 0 \\
\hline Number Failing Final Exam & 0 & 0 & 0 & 0 \\
\hline Number Incomplete * & 0 & 0 & 0 & 0 \\
\hline \multicolumn{5}{|l|}{ Enlisted: } \\
\hline Percent Passing & 93.22 & 92.00 & 96.67 & 81.40 \\
\hline Percent Failing & 6.78 & 8.00 & 3.33 & 18.60 \\
\hline Number Passing & 55 & 46 & 29 & 35 \\
\hline Number Failing & 4 & 4 & 1 & 8 \\
\hline Total (Passing + Failing) & 59 & 50 & 30 & 43 \\
\hline Number Failing Homework & 4 & 0 & 0 & 1 \\
\hline Number Failing Final Exam & 3 & 4 & 1 & 7 \\
\hline Number Incomplete * & 4 & 7 & 2 & 3 \\
\hline
\end{tabular}

*Note: Incompletes are students recalled to home command or unauthorized absences before completion of course and are not counted in other rows above. 


\section{Appendix E}

Summary Tables for Open-Ended Questionnaire Items 
Table E-1

Percentage of Treatment Group Responses to Open-Ended Question Number 41 "If you had a choice, would you take another VTT course ?"

\begin{tabular}{|c|c|c|c|}
\hline \multirow[b]{2}{*}{ Group and Comment Category } & \multicolumn{3}{|c|}{ Treatment Group } \\
\hline & VTT Local & VTT Remote & Combined Groups \\
\hline Positive Comment & 33.6 & 36.1 & 34.4 \\
\hline Negative Comment & 11.7 & 9.8 & 11.1 \\
\hline Positive and Negative & 4.7 & 11.5 & 6.9 \\
\hline No Comment & 50.0 & 42.6 & 47.6 \\
\hline Total Percent & 100.0 & 100.0 & 100.0 \\
\hline Total Students & 128 & 61 & 189 \\
\hline
\end{tabular}

Table E-2

Percentage of Students in Each Treatment Group That Offered Comments to Open-Ended Questions (Items 42, 43, and 44)

\begin{tabular}{|c|c|c|c|c|}
\hline \multirow[b]{2}{*}{ Group and Question } & \multicolumn{4}{|c|}{ Treatment Group } \\
\hline & Traditional & Local & Remote & All Groups \\
\hline 42. Liked most about course & 86.5 & 82.8 & 77.0 & 82.1 \\
\hline 43. Liked least about course & 53.8 & 67.1 & 67.2 & 64.3 \\
\hline 44. Suggestions for improvement & 44.2 & 50.0 & 60.6 & 51.4 \\
\hline Total Number of Students & 52 & 128 & 61 & 241 \\
\hline
\end{tabular}

Note: percentages of total students that gave one or more comments to a question 
Table E-3

\section{Percentage of Treatment Group Responses to Open-Ended Question "What did you like the most about this course?"}

\begin{tabular}{|c|c|c|c|c|}
\hline \multirow[b]{2}{*}{ Group and Comment Category } & \multicolumn{4}{|c|}{ Treatment Group } \\
\hline & Traditional & Local & Remote & All Groups \\
\hline a. Subject Matter & 21.7 & 31.7 & 26.1 & 28.0 \\
\hline b. Pace of Course Appropriate & 6.7 & 7.8 & 7.3 & 7.4 \\
\hline c. VTT & 0.0 & 3.5 & 16.0 & 5.9 \\
\hline d. Instructors & 21.6 & 12.0 & 7.2 & 13.0 \\
\hline e. Exercises and Practice & 8.3 & 4.9 & 2.9 & 5.2 \\
\hline f. Homework and Calculations & 5.0 & 8.5 & 4.3 & 6.4 \\
\hline g. Instructional Strategies & 18.3 & 6.3 & 4.3 & 8.5 \\
\hline h. Instructional Materials & 5.0 & 4.2 & 2.9 & 4.1 \\
\hline i. Interaction & 0.0 & 2.8 & 1.5 & 1.9 \\
\hline j. Miscellaneous & 1.7 & 2.8 & 7.2 & 3.7 \\
\hline No Comment & 11.7 & 15.5 & 20.3 & 15.9 \\
\hline Total Percent & $\overline{100.0}$ & 100.0 & $\overline{100.0}$ & $\overline{100.0}$ \\
\hline Number of 1 st Comments & 45 & 106 & 47 & 198 \\
\hline Number of 2 nd Comments & 8 & 14 & 8 & 30 \\
\hline Total Comments & 53 & 120 & 55 & 228 \\
\hline Number No Comment & 7 & 22 & 14 & 43 \\
\hline Total Comments and No Comment & 60 & $\overline{142}$ & 69 & $\overline{271}$ \\
\hline Number of Students & 52 & 128 & 61 & 241 \\
\hline
\end{tabular}

Note: Divisor for percents was total of comments and no comment

a. Subject Matter (help with job, need to know, valuable skill, theory, review, interesting, challenging).

b. Pace of Course (appropriate pace or course length, appropriate amount of material covered in time frame, covered material quickly).

c. VTT (liked VTT instruction, technology, or using VTT system).

d. Instructors (knowledge, helpfulness, teaching style, efficient).

e. Exercises and Practice (real plotting, hands-on).

f. Homework and Calculations (strip form computations, repetition helped learn, problem solving, learned new methods, challenging).

g. Instructional Strategies (step by step presentation, practical application, course organization, feedback, clarifying how to use strip forms).

h. Instructional Materials (video, handouts, visuals of strip forms, publications, revised strip forms).

i. Interaction (with instructors and distant students).

j. Miscellaneous (facilitator helped, small class size, open classroom, intense learning). 
Table E-4

Percentage of Treatment Group Responses to Open-Ended Question "What did you like the least about this course?"

\begin{tabular}{|c|c|c|c|c|}
\hline \multirow[b]{2}{*}{ Group and Comment Category } & \multicolumn{4}{|c|}{ Treatment Group } \\
\hline & Traditional & Local & Remote & All Groups \\
\hline a. Subject Matter & 3.8 & 3.0 & 0.0 & 2.4 \\
\hline b. Pace of Course Too Fast & 11.3 & 10.6 & 17.2 & 12.5 \\
\hline c. VTT & 0.0 & 6.8 & 4.7 & 4.8 \\
\hline d. Instructors & 0.0 & 4.5 & 12.5 & 5.6 \\
\hline e. Exercises and Practice & 5.7 & 0.8 & 1.6 & 2.0 \\
\hline f. Homework and Calculations & 18.9 & 19.7 & 15.6 & 18.5 \\
\hline g. Instructional Strategies & 3.7 & 0.8 & 1.6 & 1.6 \\
\hline h. Instructional Materials & 3.7 & 2.3 & 3.1 & 2.8 \\
\hline i. Facilities & 0.0 & 11.4 & 0.0 & 6.0 \\
\hline j. Limited Access & 1.9 & 3.8 & 1.6 & 2.8 \\
\hline k. Facilitators & 0.0 & 0.0 & 3.1 & 0.8 \\
\hline 1. Miscellaneous & 5.7 & 4.5 & 7.8 & 5.6 \\
\hline No Comment & 45.3 & 31.8 & 31.2 & 34.6 \\
\hline Total Percent & 100.0 & 100.0 & 100.0 & 100.0 \\
\hline Number of 1st Comments & 28 & 86 & 41 & 155 \\
\hline Number of 2 nd Comments & 1 & 4 & 3 & 8 \\
\hline Total Comments & 29 & 90 & 44 & 163 \\
\hline Number No Comment & 24 & 42 & 20 & 86 \\
\hline Total Comments and No Comment & 53 & 132 & 64 & 249 \\
\hline Number of Students & 52 & 128 & 61 & 241 \\
\hline
\end{tabular}

Note: Divisor for percents was total of comments and no comment

a. Subject Matter (too hard, more theory, explain terminology, pay attention to every detail).

b. Pace of Course (too fast, course too short).

c. VTT (delays, technical difficulties, using microphone to talk, could not see other students).

d. Instructors (knowledge of some topics, use of VTT system, getting help, teaching style).

e. Exercises and Practice (not enough plotting or hands-on, no actual shooting using sextant).

f. Homework and Calculations (repetitive calculations, too much or too difficult, concentrated in a few days, not realistic, no chance to ask questions on it).

g. Instructional Strategies (organization, limited practical applications, no computer use).

h. Instructional Materials (video outdated, not interesting).

i. Facilities (small tables, room too small, room too warm).

j. Limited Access to Classroom (to do homework during or after class, closed too early).

k. Facilitators (lack of subject knowledge).

1. Miscellaneous (dress requirements, travel, too slow, test answers, more course offerings, slow students need prerequisite knowledge, emphasis on new strip forms). 
Table E-5

\section{Percentage of Treatment Group Responses to Open-Ended Question "Discuss any suggestions you have for improving the course"}

\begin{tabular}{|c|c|c|c|c|}
\hline \multirow[b]{2}{*}{ Group and Comment Category } & \multicolumn{4}{|c|}{ Treatment Group } \\
\hline & Traditional & Local & Remote & All Groups \\
\hline a. Subject Matter & 7.3 & 5.8 & 2.9 & 5.3 \\
\hline b. Pace of Course Slower & 5.5 & 6.5 & 7.3 & 6.5 \\
\hline c. VTT & 0.0 & 5.1 & 4.3 & 3.8 \\
\hline d. Instructors & 0.0 & 1.5 & 8.7 & 3.1 \\
\hline e. Exercises and Practice & 9.1 & 3.6 & 2.9 & 4.6 \\
\hline f. Instructional Strategies & 12.7 & 10.9 & 5.8 & 9.9 \\
\hline g. Instructional Materials & 7.3 & 2.9 & 13.0 & 6.5 \\
\hline h. Facilities & 0.0 & 8.7 & 1.5 & 4.9 \\
\hline i. Facilitators & 0.0 & 0.7 & 13.0 & 3.8 \\
\hline j. Access to Room & 3.6 & 3.6 & 0.0 & 2.7 \\
\hline k. Miscellaneous & 1.8 & 4.3 & 5.8 & 4.2 \\
\hline No Comment & 52.7 & 46.4 & 34.8 & 44.7 \\
\hline Total Percent & 100.0 & 100.0 & 100.0 & 100.0 \\
\hline Number of 1 st Comments & 23 & 64 & 37 & 124 \\
\hline Number of 2 nd Comments & 3 & 9 & 7 & 19 \\
\hline Number of 3rd Comments & 0 & 1 & 1 & 2 \\
\hline Total Comments & 26 & 74 & $\overline{45}$ & 145 \\
\hline Number No Comment & 29 & 64 & 24 & 117 \\
\hline Total Comments and No Comment & 55 & 138 & 69 & $\overline{262}$ \\
\hline Number of Students & 52 & 128 & 61 & 241 \\
\hline
\end{tabular}

Note: Divisor for percents was total of comments and no comment

a. Subject Matter (more theory, readings, or explain reference pubs, lifeboat navigation).

b. Pace of Course (slower or increase course length).

c. VTT (audio, non-glare monitors, view of local students for remote site, sound activated microphones, computer model showing hour angles, prefer traditional class).

d. Instructor (assist students, help with homework, avoid redundancy, available after class).

e. Exercises and Practice (more plotting, hands-on work shooting with sextant).

f. Instructional Strategies (order of topics, plot sooner, more on plotting rules, less homework, review homework, homework checksum, pace to student ability, new celestial technology).

g. Instructional Materials (extra strip forms for practice, better plotting tools, new videotape, separate homework and notetaking sheets, reference books).

h. Facilities (larger tables, more work space, adjust room temperature).

i. Facilitators (more knowledge of material, knowledgeable person for remote site).

j. Access to Classroom (more access to classroom for doing homework).

k. Miscellaneous (relate to Coast Guard, grade less on plotting, basic course as prerequisite, expand VTT, faster pace, use PIP view, pass skill to shipmates, piloting-magnetic topic). 


\section{Appendix F}

\section{Interaction Tally Summary Statistics}


Table F-1

Interaction Tally Category Numbers Used in Tables

Instructor Question Categories (1, 2, 3) answered from either Local or Remote site:

(1) Open to Any Site

(2) Names a Site

(3) Specific Student

Student Questions Categories $(4,5)$ from either Local or Remote Site:

(4) Student Initiated

(5) Conversations

Other Categories (6 and 7 combine Local and Remote)(8 for Local Only):

(6) No Answer to Instructor Question

(7) No Answer to Instructor Query for "Any Questions"

(8) Instructor Reminds Local Student to Use Microphone

Note: Definitions for these categories are given in the method section.

Table F-2

\section{Correlation Between Observer Interaction Tallies}

\begin{tabular}{llccc}
\hline \multicolumn{1}{c}{ Interaction Category } & & $\begin{array}{c}\text { Number of } \\
\text { Observations }\end{array}$ & & Correlation \\
\cline { 1 - 1 } (1) Instructor Question Open to Any Site & & 6 & & 0.939 \\
(2) Instructor Question Names a Site & & 6 & & 0.981 \\
(3) Instructor Questions Specific Student & & 6 & & 0.980 \\
(4) Student Initiated Questions & & 6 & & 0.993 \\
(5) Student Conversations and Exchanges & & 6 & & 0.667 \\
\cline { 1 - 2 } Combined Over All 5 Categories & & 30 & & 0.975 \\
\hline
\end{tabular}

Explanation of Table F-2: Rater agreement using the interaction tally was recorded during three half day periods (two afternoon sessions and one morning session). Pearson correlation coefficients were calculated for two raters observing the same sessions in which there was one local and one remote site (perfect correspondence between raters would be indicated by a coefficient of +1.0 ). The 0.975 correlation between rater interaction frequencies was based on an overall total of 30 pairs of observations where each rater made observations for five tally categories by two sites by three recording periods. Of 414 total interactions, one rater recorded 209 and the other recorded 205. The correlations for the individual categories were based on six observations in each category (i.e., two sites by three recording periods for each rater). 
Table F-3

Interaction Frequencies and Percentages by Individual Category

Category

Instructor Questions (1 to 3):

(1) Open to Any Site

Local

Remote

Subtotal Local + Remote

(2) Names a Site

Local

Remote

Subtotal Local + Remote

(3) Specific Student

Local

Remote

Subtotal Local + Remote

\section{Percent of All Percent of Only \\ Frequency Categories 1 to 8 Categories 1 to 5}

$\begin{array}{lrr}514 & 14.9 \% & 18.1 \% \\ \frac{392}{906} & \frac{11.4 \%}{26.4 \%} & \frac{13.8 \%}{31.8 \%} \\ 123 & 3.6 \% & 4.3 \% \\ \frac{440}{563} & \frac{12.8 \%}{16.4 \%} & \frac{15.5 \%}{19.8 \%} \\ 494 & 14.4 \% & 17.3 \% \\ \frac{255}{749} & \frac{7.4 \%}{21.8 \%} & \frac{8.9 \%}{26.3 \%}\end{array}$

Student Questions (4 and 5):

(4) Student Initiated

Local

Remote

296

160

$8.6 \%$

$10.4 \%$

Subtotal Local + Remote

$\frac{4.7 \%}{13.3 \%}$

$\frac{5.6 \%}{16.0 \%}$

(5) Conversations/Exchanges

Local

Remote

Subtotal Local + Remote

79

94

$2.3 \%$

$2.8 \%$

173

$\frac{2.7 \%}{5.1 \%}$

$\frac{3.3 \%}{6.1 \%}$

Subtotal Categories (1 to 5)

$\overline{\overline{2847}}$

$\overline{83 \%}$

$\overline{100 \%}$

Other Categories (6 to 8):

(6) No Answer to

Instructor Question

(7) No Answer to Instructor

"Any Questions" Query

(8) Microphone Reminders

to Local Students

132

$3.9 \%$

334

$9.7 \%$

115

$3.4 \%$

Grand Total Categories ( 1 to 8 )

$\overline{\overline{3428}}$

$\overline{\overline{100 \%}}$

Frequencies are sums for six classes. Percents may not add to $100 \%$ due to rounding. 
Table F-4

Interaction Frequencies and Percentages by Combined Category

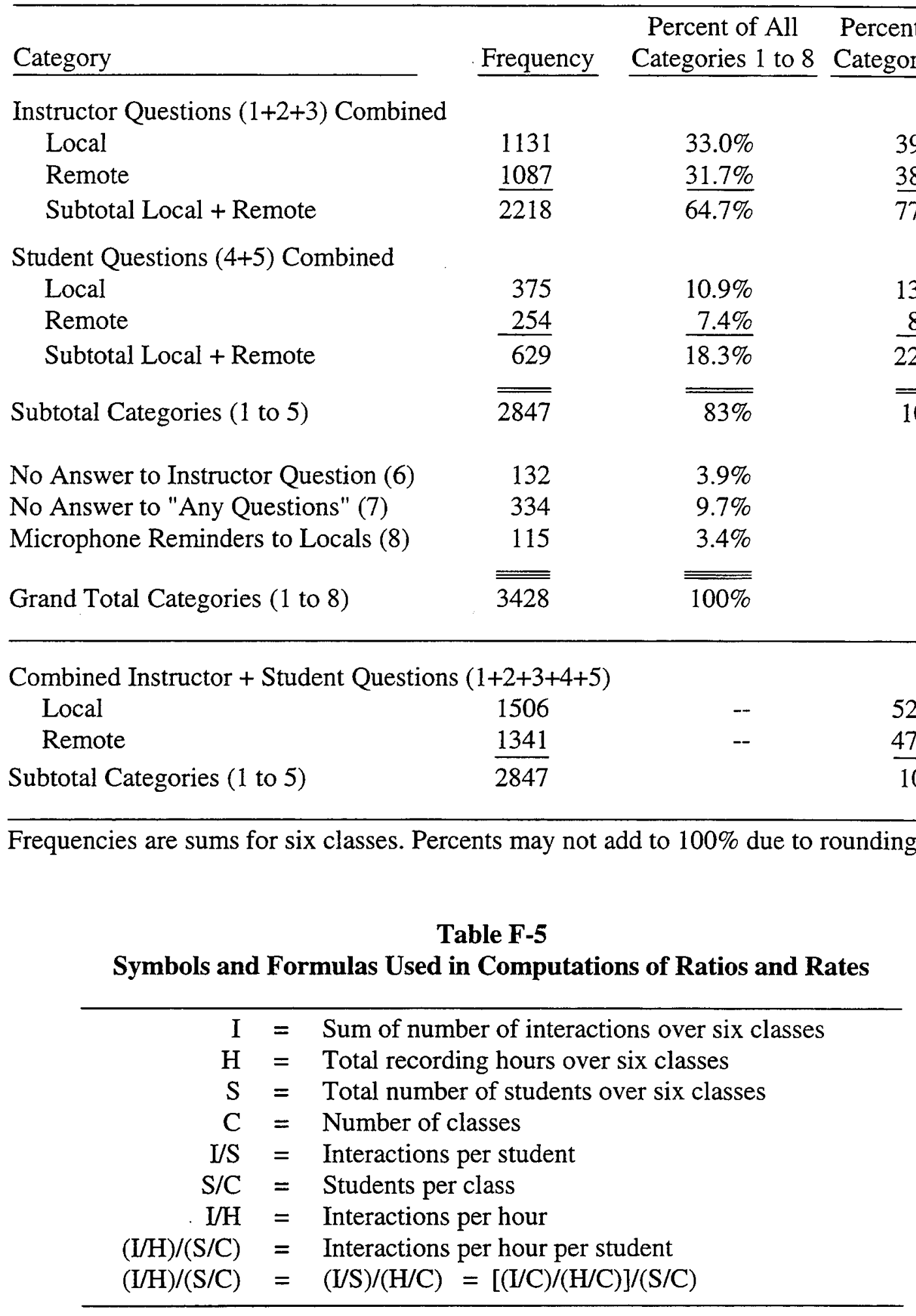


Table F-6

Computation of Instructor and Student Question Ratios

Measure

Sum of Interactions (I)

Total Students (S)

Number of Classes (C)

Students Per Class (S/C)

Total Recording Hours (H)

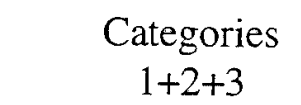

Instructor

Questions

\begin{tabular}{rr}
\multicolumn{2}{c}{ Questions } \\
\hline Local & Remote \\
1131 & 1087 \\
101 & 46 \\
6 & 6 \\
16.83 & 7.66 \\
53.016 & 53.016
\end{tabular}

Categories

$4+5$

Student

Questions

$\frac{\text { Local }}{375} \quad \frac{\text { Remote }}{254}$

375

101

6

16.83

53.016

254
46

7.66
53.016

6
.66

53.016

Interaction Ratios:

$\begin{array}{lrrrrrr}\text { Per Student (I/S) } & 11.19 & 23.63 & 3.71 & 5.52 & 14.91 & 29.15 \\ \text { Per Hour (I/H) } & 21.33 & 20.50 & 7.07 & 4.79 & 28.40 & 25.29 \\ \text { Per Hour Per Student } & 1.267 & 2.674 & 0.420 & 0.624 & 1.687 & 3.299 \\ \quad[(\mathrm{I} / \mathrm{H}) /(\mathrm{S} / \mathrm{C})] & & & & & & \end{array}$

$11.19 \quad 23.63$

21.33

20.50

[(I/H)/(S/C)]

\section{-}


Table F-8

Interaction Rates by Category for Local and Remote

\begin{tabular}{|c|c|c|c|c|}
\hline \multirow[b]{2}{*}{ Category } & \multicolumn{2}{|c|}{$\begin{array}{c}\text { Per Hour } \\
(\mathrm{I} / \mathrm{H})\end{array}$} & \multicolumn{2}{|c|}{$\begin{array}{c}\text { Per Hour } \\
\text { Per Student } \\
(\mathrm{I} / \mathrm{H}) /(\mathrm{S} / \mathrm{C})\end{array}$} \\
\hline & Local & Remote & Local & Remote \\
\hline \multicolumn{5}{|l|}{ Instructor Questions: } \\
\hline (1) Open to Any Site & 9.69 & 7.39 & 0.57 & 0.96 \\
\hline (2) Names a Site & 2.32 & 8.29 & 0.13 & 1.08 \\
\hline (3) Specific Student & 9.31 & 4.80 & 0.55 & 0.62 \\
\hline \multicolumn{5}{|l|}{ Student Questions: } \\
\hline (4) Student Initiated & 5.58 & 3.01 & 0.33 & 0.39 \\
\hline (5) Conversations and Exchanges & 1.49 & 1.77 & 0.08 & 0.23 \\
\hline
\end{tabular}

Table F-9

Interaction Rates by Days by Morning (AM) and Afternoon (PM)

\begin{tabular}{|c|c|c|c|c|c|c|}
\hline \multirow[b]{2}{*}{ Measure and Category } & \multicolumn{2}{|c|}{ Day 1} & \multicolumn{2}{|c|}{ Day 2} & \multicolumn{2}{|c|}{ Day 3} \\
\hline & $\mathrm{AM}$ & $\mathrm{PM}$ & AM & $\mathrm{PM}$ & $\mathrm{AM}$ & PM \\
\hline Total Recording Hours & 11.01 & 7.07 & 13.95 & 7.74 & 8.59 & 4.85 \\
\hline \multicolumn{7}{|l|}{ Interactions Per Hour $(\mathbf{I} / \mathrm{H})$} \\
\hline $\begin{array}{l}\text { Instructor and Student } \\
\quad(\text { Categories } 1+2+3+4+5)\end{array}$ & 40.96 & 55.02 & 54.76 & 51.03 & 66.23 & 66.59 \\
\hline No Answer to Instructor Question (6) & 5.35 & 3.11 & 1.43 & 1.16 & 1.74 & 1.03 \\
\hline No Answer to "Any Questions" (7) & 5.90 & 4.66 & 5.80 & 5.81 & 8.14 & 8.24 \\
\hline Microphone Reminders to Locals (8) & 2.99 & 2.40 & 2.07 & 2.06 & 1.51 & 1.44 \\
\hline \multicolumn{7}{|c|}{ Interactions Per Hour Per Student $(\mathrm{I} / \mathrm{H}) /(\mathrm{S} / \mathrm{C})$} \\
\hline $\begin{array}{l}\text { Instructor and Student } \\
\text { (Categories } 1+2+3+4+5)\end{array}$ & 1.67 & 224 & 223 & 208 & 270 & 2 \\
\hline No Answer to Instructor Question (6) & 0.22 & 0.13 & 0.06 & 0.05 & 0.07 & 0.04 \\
\hline No Answer to "Any Questions" (7) & 0.24 & 0.19 & 0.24 & 0.24 & 0.33 & 0.34 \\
\hline Microphone Reminders to Locals (8) & 0.17 & 0.14 & 0.12 & 0.12 & 0.09 & 0.08 \\
\hline
\end{tabular}


Table F-10

Interaction Rates by Days

\begin{tabular}{|c|c|c|c|}
\hline Interactions Per Hour (U/H) & Day 1 & Day 2 & Day 3 \\
\hline \multicolumn{4}{|l|}{ Instructor Questions (Categories $1+2+3$ ) } \\
\hline Local: & 19.72 & 20.52 & 27.81 \\
\hline Remote: & 19.17 & 18.61 & 23.88 \\
\hline Combined Local and Remote: & 38.89 & 39.14 & 52.43 \\
\hline \multicolumn{4}{|l|}{ Student Questions (Categories 4+5) } \\
\hline Local: & 4.08 & 9.33 & 7.49 \\
\hline Remote: & 3.42 & 5.08 & 6.15 \\
\hline Combined Local and Remote: & 7.51 & 14.41 & 13.64 \\
\hline \multicolumn{4}{|l|}{ Other Categories $(6,7,8)$} \\
\hline No Answer to Instructor Question (6) & 4.53 & 1.30 & 1.48 \\
\hline No Answer to "Any Questions" Query (7) & 5.41 & 5.87 & 8.15 \\
\hline Microphone Reminders to Local Students (8) & 2.76 & 2.09 & 1.48 \\
\hline Interactions Per Hour Per Student $(\mathrm{I} / \mathrm{H}) /(\mathrm{S} / \mathrm{C})$ & Day 1 & Day 2 & Day 3 \\
\hline \multicolumn{4}{|l|}{ Instructor Questions (Categories $1+2+3$ ) } \\
\hline Local: & 1.17 & 1.21 & 1.66 \\
\hline Remote: & 2.50 & 2.48 & 3.28 \\
\hline Combined Local and Remote: & 1.58 & 1.60 & 2.16 \\
\hline \multicolumn{4}{|l|}{ Student Questions (Categories 4+5) } \\
\hline Local: & 0.24 & 0.55 & 0.44 \\
\hline Remote: & 0.44 & 0.67 & 0.82 \\
\hline Combined Local and Remote: & 0.30 & 0.59 & 0.56 \\
\hline \multicolumn{4}{|l|}{ Other Categories $(6,7,8)$} \\
\hline No Answer to Instructor Question (6) & 0.18 & 0.05 & 0.06 \\
\hline No Answer to "Any Questions" Query (7) & 0.22 & 0.23 & 0.33 \\
\hline Microphone Reminders to Local Students (8) & 0.16 & 0.12 & 0.08 \\
\hline
\end{tabular}




\section{Distribution List}

Chief of Naval Operations (N813)

Office of Naval Research (Code 03B) (3)

Chief of Naval Education and Training (Code 00), (N2), (N5), (L01) (12)

Chief of Naval Personnel (PERS-00H), (PERS-05)

Commander, Naval Reserve Force, New Orleans

Commander, Training Command, U.S. Atlantic Fleet

Commander, Training Command, U.S. Pacific Fleet (Code N-31)

Commanding General, Marine Corps Combat Development Command (MCCDC), Quantico

Commanding Officer, Naval Education and Training Program Management Support Activity (Code 04) (2), (Code 03EE1) (2)

Commanding Officer, Fleet Anti-Submarine Warfare Training Center, Atlantic

Commanding Officer, Fleet Anti-Submarine Warfare Training Center, Pacific

Commanding Officer, Submarine Training Facility, San Diego

Commanding Officer, Fleet Combat Training Center, Atlantic (Code N713)

Commanding Officer, Fleet Training Center, San Diego (Code 00), (021.2)

Commanding Officer, Fleet Training Center, Curriculum and Instructional Standards Office, Norfolk

Commanding Officer, Navy Air Warfare Center, Training Systems Division (Technical Library) (Code 72) (5)

Commanding Officer, Sea-Based Weapons and Advanced Tactics School, Pacific

Superintendent, Naval Postgraduate School

Director of Research, U.S. Naval Academy

Center for Naval Analyses, Acquisition Unit

Director, Defense Personnel Security Research Center

Director, Army Research Institute (PERI-ZT), (PERI-II), Alexandria

Director, Human Resources Directorate, Armstrong Laboratory (AL/HR), (AL/HR-DOKL Technical Library), Brooks Air Force Base, TX

Headquarters, Air Education and Training Command (AETC/XORR), (AETC/TTP), Randolph Air Force Base, TX

Pentagon Library

Defense Technical Information Center (DTIC) (4) 